PALABRAS CLAVE

Empresas transnacionales Mercados emergentes Inversión extranjera directa Inversiones

Empresas comerciales Empresas industriales Datos estadísticos

Brasil

México

América Latina

España

Javier Santiso

Director y Economista Jefe,

Centro de Desarrollo,

Organización de Cooperación

y Desarrollo Económicos (OCDE)

$\nsim$ javier.santiso@oecd.org
REVISTA DE LA CEPAL 95 A AOSTO 2008

\section{La emergencia de las multilatinas}

\author{
Javier Santiso
}

$\mathrm{E}$

mundo empresarial cambió notablemente en los últimos diez años. Han surgido nuevas empresas multinacionales en países de mercados emergentes como Brasil, India, China, Sudáfrica y México, los que no solo son grandes receptores de capital extranjero sino que ahora también invierten fuertemente en el exterior. En la notable historia de las nuevas multinacionales destaca la aparición de empresas que Ilamaremos multinacionales latinas (o multilatinas), en particular de México y Brasil, que tuvieron como precedente aquellas de España en los años 1990. Las multilatinas surgieron merced a los clásicos factores de expulsión y atracción (push and pull). Pero en la última década fueron impulsadas por la baja del costo del capital, que está activando el salto desde las ventas en el exterior a las adquisiciones en el exterior, fenómeno que es materia del presente artículo. 


\section{I}

\section{Introducción}

El mundo empresarial cambió de manera extraordinaria en la última década. Están surgiendo nuevas multinacionales en países como Brasil, India, China, Sudáfrica y México, con lo que se altera rápidamente todo el tablero mundial de empresas.

En algunos sectores, como los del acero y el cemento, los líderes mundiales no son ya empresas de países desarrollados. Por ejemplo, en el 2006, el grupo indio Mittal asumió el control de su rival europea Arcelor para transformarse en líder del sector del acero, en tanto que en el sector del cemento, Cemex de México alcanzó a gigantes como Lafarge (francesa) y Holcim (suiza). En el 2006, la compra de la empresa Inco, con base en Canadá, colocó al conglomerado minero brasileño Compañía Vale do Rio Doce (en adelante Vale) en la cúspide de las categorías internacionales, junto a las angloaustralianas BHP Billiton y Río Tinto. En el 2007 y el 2008, el grupo indio Tata se adueñó de las joyas de la industria británica del acero y del automóvil, en tanto que en Asia, conglomerados surcoreanos como Samsung y LG o Posco son ahora pesos pesados mundiales, seguidos de cerca por empresas chinas de la próxima generación, como Huawei o Lenovo.

Los países de mercados emergentes no solo son lugar de destino del capital extranjero, sino que se han transformado con rapidez en inversores importantes en el exterior. Como receptores potenciales de la inversión mundial, en el 2008, China e India ocupan el primero y segundo lugar, seguidos de cerca por los Estados Unidos; estos dos países emergentes son así los lugares preferidos donde los empresarios de las grandes empresas planean invertir en el futuro. ${ }^{1}$ Por primera vez en su historia, América Latina registró más de 100.000 millones de dólares en entradas de

\footnotetext{
$\square$ Por los documentos, comentarios y sugerencias, quisiéramos agradecer a Felipe Aldunate, José María Álvarez Pallete, Rolando Avendaño, Fernando Bergasa, Juan Luis Cardenote, Alejandro de la Sota Rius, Thomas Dickinson, Susana García, José Gasset, Jesús González Nieto-Márquez, Mauro Guillén, Jesús Mallol, David Martínez Turégano, Patrizia Labella, Juan Antonio Merino, Juan Antonio Mielgo, Javier Nadal, Vitalino Nafría, Elizabeth Nash, Marina Urquidi, Luis Rivera, Juan Antonio Rodríguez, José Juan Ruiz, Alberto Toca y un juez anónimo designado por la Revista de la CEPAL. El raciocinio, las opiniones y los posibles errores del presente trabajo son, naturalmente, de exclusiva responsabilidad del autor.

${ }^{1}$ Véase AT Kearney (2008a).
}

inversión extranjera directa (IED). También Brasil y México ocuparon lugares expectables (sexto y decimonoveno, respectivamente). Como inversores, estos mismos países emergentes de primera línea viven un auge de sus propias corrientes de inversión directa en el exterior, las cuales en algunos casos superan las entradas de capital extranjero.

La IED en mercados emergentes por parte de empresas de otros países emergentes se triplicó entre 1995 y el 2003, pasando de 15.000 millones de dólares a más de 45.000 millones de dólares. En el mismo período, la inversión de esas empresas en países de la OCDE subió de 1.000 millones de dólares a 16.000 millones. En el 2005, de acuerdo con cifras de la Conferencia de las Naciones Unidas de Comercio y Desarrollo (UNCTAD), la inversión directa de países emergentes en el extranjero llegó a la cifra sin precedentes de 133.000 millones de dólares, es decir, el $17 \%$ de las corrientes mundiales hacia el exterior. En el 2006, la IED (incluidas fusiones y adquisiciones) de las economías en desarrollo había alcanzado a 174.000 millones de dólares, un $14 \%$ del total mundial, lo que significó para esos países una participación de $13 \%$ (por valor de 1,6 billones de dólares) en el acervo mundial de IED. Colocando estas cifras en contexto, diremos que en 1990 las economías emergentes representaban $8 \%$ del acervo total y $5 \%$ de las corrientes de este tipo de inversión. ${ }^{2}$

Los países emergentes de Asia dominan este fenómeno (en el 2005 generaban más de $60 \%$ del acervo de IED de las economías emergentes), pero América Latina también se muestra dinámica en torno a esta nueva tendencia. Según la CEPAL, en el 2007 la inversión directa de Brasil en el exterior alcanzó a cerca de 7.000 millones de dólares y la de México a casi 5.000 millones. En el 2006, la inversión directa en el exterior de Brasil (28.000 millones de dólares) superó las entradas de IED en el país (19.000 millones de dólares). En el 2006, la IED de multinacionales latinoamericanas alcanzó un récord de casi 42.000 millones de dólares debido a importantes adquisiciones, incluida la de Inco por Vale do Rio Doce. ${ }^{3}$

\footnotetext{
${ }^{2}$ Véase un análisis de esta tendencia en Gammeltoft (2008).

${ }^{3}$ Véase más detalles en CEPAL (2008).
} 
Un corolario de esta tendencia es el auge de las corrientes de inversión Sur-Sur. Después de la asiática, la de América Latina es la mayor corriente de IED desde mercados emergentes, y ha estado encabezada por Argentina, Brasil y México. El número de empresas de economías emergentes en las clasificaciones mundiales aumenta junto con sus inversiones en el exterior: en 1990, solo unas pocas y felices multinacionales emergentes de países en desarrollo figuraban entre las Fortune 500; en el 2005 ya eran 47.

Una parte importante de la extraordinaria trayectoria de las multinacionales emergentes ha sido el surgimiento de multinacionales latinas de nivel mundial, de México, Brasil y, especialmente, de España. Hasta mediados de la década de 1970, España seguía siendo oficialmente un país en desarrollo de mercado emergente y figuraba como tal en el Banco Mundial y en la Corporación Financiera Internacional (CFI). De las calmas aguas en que se encontraban en esa época España y América Latina surgieron las multilatinas, empresas de países latinos de Europa o América que registraron un enorme crecimiento e internacionalización.

En este artículo se explora el surgimiento de estas nuevas multinacionales latinas. Aunque no es un fenómeno totalmente nuevo (las empresas latinas están presentes en el comercio mundial desde hace siglos), las multilatinas de hoy manejan un poderío fabril y financiero que compite con los conglomerados más grandes del mundo desarrollado. La expansión de las empresas españolas - primero en Europa y luego en América Latina - recibió impulso de factores potentes (la integración europea y la privatización y desregulación del sector servicios en América Latina) que no son los mismos que hoy explican la internacionalización de las empresas latinoamericanas (los mercados internos pequeños, la dinámica del mercado de recursos naturales para los exportadores) y de sus contrapartes asiáticas. Sin embargo, la espectacular transformación de las multilatinas en los últimos 25 años ha cambiado a los países latinos y al mundo. Analizaremos las características de este fenómeno a través de los casos de España, Brasil y México.

\section{II}

\section{El ascenso de las economías emergentes y de las multilatinas: hechos estilizados y publicaciones sobre el tema}

Actualmente, las variaciones en la riqueza de las naciones se perciben con claridad, sobre todo en la espectacular aparición de las multinacionales de países emergentes. Su expansión va desde las manufacturas al financiamiento de empresas: en el 2007, cuando el aumento mundial de las adquisiciones era de $6 \%$, el de las multinacionales emergentes fue de más de $26 \%$. $^{4}$ Según AT Kearney (2008a), en el 2007 el 20\% de las 2.200 adquisiciones entre países desarrollados y países en desarrollo estuvieron impulsadas por multinacionales de mercados emergentes. La mayor contribución puede atribuirse a China, India y Malasia, que entre el 2002 y el 2007 representaron $56 \%$ del total de adquisiciones originadas en países emergentes.

\footnotetext{
${ }^{4}$ Véase AT Kearney (2008b).
}

La reciente serie de fusiones y adquisiciones transfronterizas de gran visibilidad en las que han participado empresas chinas e indias ilustra bien esta tendencia. El Boston Consulting Group (2006a y 2006b), en un estudio de las 100 principales multinacionales emergentes, identificó 44 de China, seguida por India (21), Brasil (11) y México (6). América Latina, con un total de 18 compañías en la lista, queda debajo de Asia (70) pero por encima de otras regiones (las 12 empresas restantes pertenecen a una amplia gama de países, como Egipto, Rusia, Sudáfrica y Turquía).

Las necesidades energéticas y la competencia interna han sido los acicates de la expansión de India y China en el exterior (gráfico 1). En el caso de China, la ambición de crear empresas nacionales de primer nivel sirvió de acelerador. Como subraya el Deutsche Bank Research (2006), están surgiendo empresas chinas de primera línea y la corriente de inversiones de estas empresas en el 
GRÁFICO 1

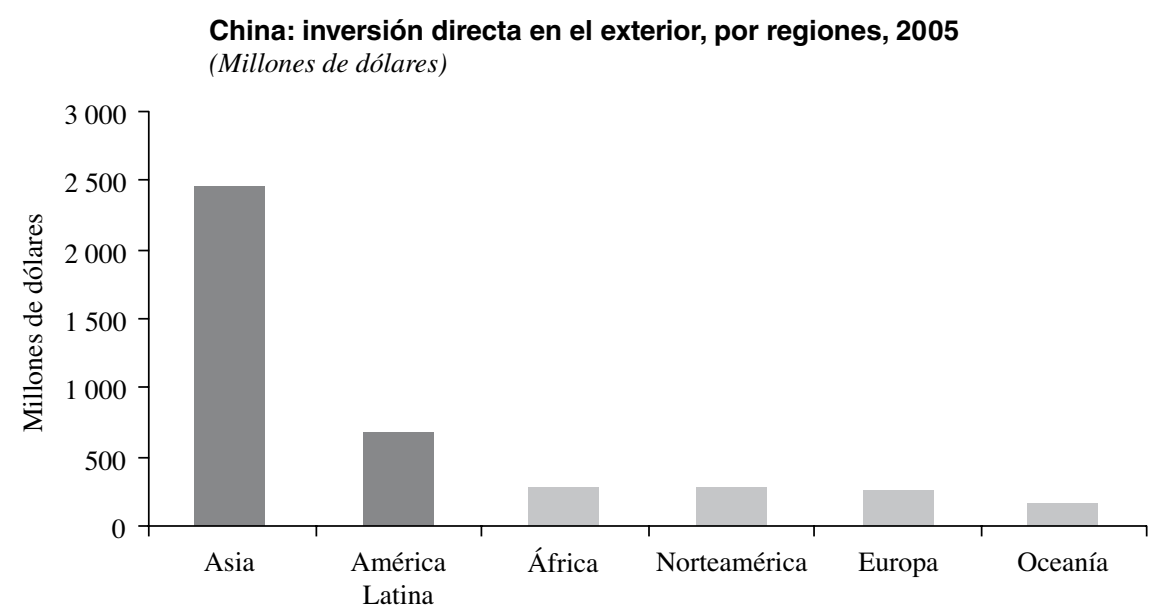

Fuente: elaboración propia sobre la base de datos oficiales chinos, año 2006.

GRÁFICO 2

India: ingresos de sus empresas multinacionales en las diferentes regiones (Miles de millones de rupias)

Consultora Tata

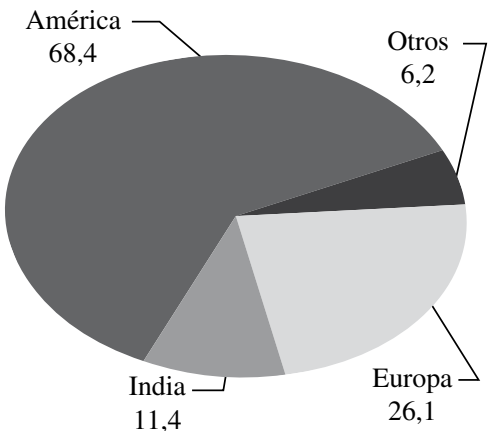

Wypro

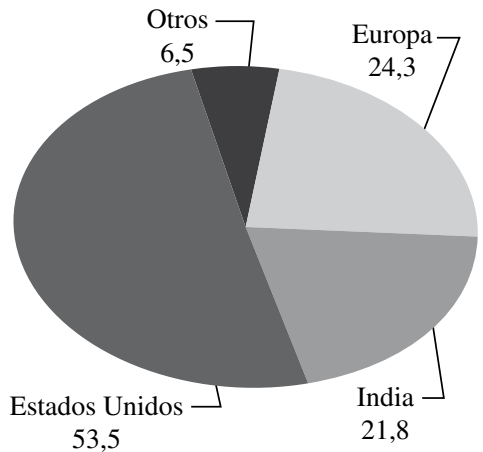

Infosys

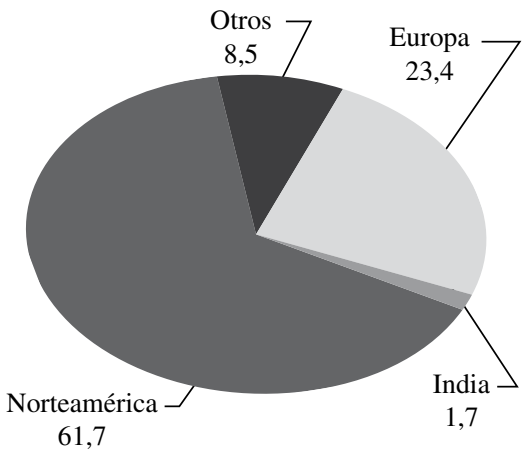

Fuente: elaboración propia sobre la base de informes anuales de las empresas, 2006.

exterior aumenta año a año. Según el Boston Consulting Group (2006a), a partir de 1986 las empresas chinas han realizado más de 220 adquisiciones en su expansión en el exterior, por un valor total de unos 18.000 millones de dólares. ${ }^{5}$ América Latina se está beneficiando de las atenciones de China: en el 2005, la región era la segunda receptora de IED proveniente de ese país, después de Asia (el año anterior estaba delante de Asia).

El caso de India es igualmente espectacular (gráficos 2 y 3 y cuadro 1). Algunas empresas indias

\footnotetext{
${ }^{5}$ Véase Boston Consulting Group (2006a).
}

ya se han orientado decididamente a los mercados externos. Grupos informáticos indios como Infosys, Tata Consultancy Services (TCS) y Wypro generan ya, respectivamente, $98 \%, 90 \%$ y $80 \%$ de sus ingresos en mercados fuera de su país (gráfico 2). En su gran interés por América Latina también incide que estén creando centros de desarrollo en husos horarios cercanos a sus principales mercados, que facilitan la prestación de servicios a América Latina y especialmente a los Estados Unidos. Las empresas indias también están invirtiendo con fuerza en el exterior (Tata Consultancy Services, por ejemplo, tiene 1.100 empleados en Brasil y 250 en Uruguay). América Latina atrae una parte sustancial de 
la IED india, esencialmente en los sectores relacionados con productos básicos como petróleo, minerales y gas, siendo Brasil, Colombia y Bolivia los principales destinos.

El aumento sustancial de las actividades de las multilatinas está registrado en clasificaciones mundiales como la lista de Forbes de las 2.000 empresas más importantes del mundo, que incluye unas 30 de España y alrededor de 20 de México y Brasil (gráfico 4).

Detrás del surgimiento de las multilatinas existe un esquema de expulsión y atracción no muy distinto

GRÁFICO 3
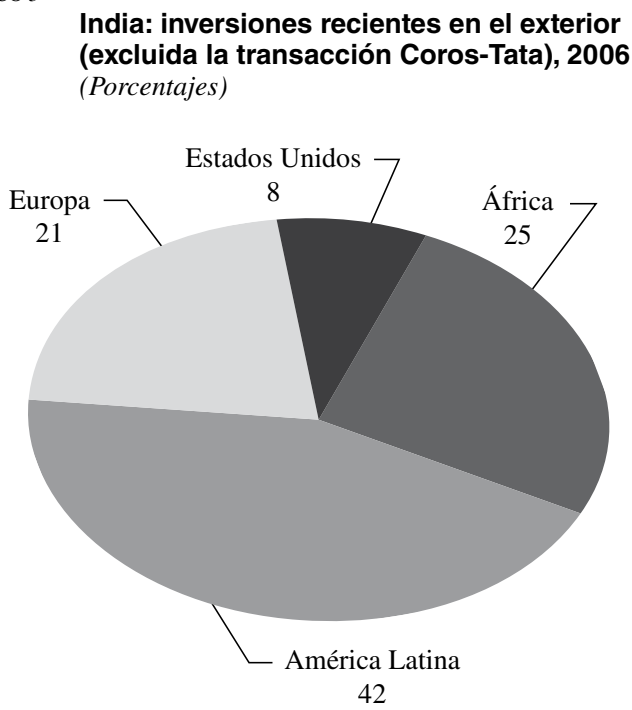

Fuente: estimaciones propias sobre la base del sitio web Dealogic y del Financial Times (varios números del 2006). del analizado en las publicaciones tradicionales sobre la internacionalización empresarial. La mayoría de los estudios de la última década se basan en publicaciones anteriores sobre la aparición de multinacionales del mundo en desarrollo - cuya primera generación apareció hace unos 20 años - y subrayan factores como las habilidades adquiridas en mercados protegidos, que les dan ventajas competitivas en otros mercados protegidos (Lall, 1983; Wells, 1983). Recurriendo al modelo del ciclo de producción (Vernon, 1966), esos

\section{Algunos países: número de sus empresas incluidas en Forbes 2000}

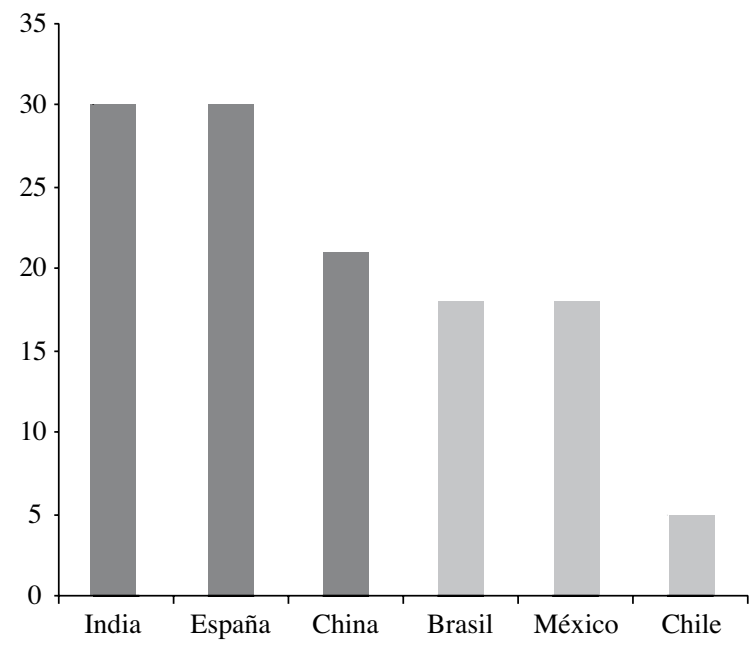

Fuente: Forbes, lista de las 2.000 mayores empresas, 2006.

CUADRO 1

India: auge de la inversión directa en el exterior, 2006

(Millones de dólares)

\begin{tabular}{lllr}
\hline Corus & Reino Unido/Nueva Zelandia & Grupo Tata & 7700 \\
Oil \& Gas Assets (Campos Basin) & Brasil & Oil \& Natural Gas Corp & 1670 \\
Omnimex de Colombia & Colombia & Oil \& Natural Gas Corp: China Group & 850 \\
Oil \& Gas Assets (Brasil) & Brasil & ONGC Videsh & 820 \\
Greater Nile Petroleum (25\%) & Sudán & Oil \& Natural Gas Corp & 783 \\
Glaceau (30\%) & Estados Unidos & Tata tea & 677 \\
Shell Development Angola & Angola & Oil \& Natural Gas Corp & 600 \\
Oil \& Gas Assets (Syria) & Siria & Oil \& Natural Gas Corp: China Group \\
Betapharm Arzneimittel & Alemania & Dr Reddy's Lab & 581 \\
Hansen Transmissions & Bélgica & Suzlon Energy & 572 \\
Eve Holding & Bélgica & Suzlon Energy & 562 \\
Terapia & Rumania & Ranbaxy & 548 \\
Total & & & 324 \\
\hline
\end{tabular}

Fuente: estimaciones propias sobre la base del sitio web Dealogic y del Financial Times (varios números del 2006). 
análisis también insistían en la capacidad de algunas empresas de los países en desarrollo para aprovechar sus bajos costos y adaptar las tecnologías de elaboración y producción existentes. Pero la mayor parte de los argumentos invocados están quedando obsoletos, a pesar de que estudios más recientes (Goldstein, 2007) demuestran que otros siguen siendo válidos, en especial la insistencia en la tecnología como principal motor de la expansión a países con menos nivel de desarrollo (Tolentino, 1993; Oman, 1986).

En el período transcurrido desde esa época, surgió el denominado paradigma ecléctico como la más influyente teoría relativa a la internacionalización de las multinacionales emergentes (Cuervo-Cazurra y Genc, 2008; Aulakh (2007) y Jones (2005), continuando estudios de Dunning (1995, 1980 y 1979). Sobre la base de la economía de los costos de transacción derivada del fecundo trabajo de Coase (1994), este enfoque conceptualiza la decisión de invertir en el exterior en términos de factores de mercado, de producción y sectoriales. Las empresas empiezan por exportar a un país y luego establecen la producción localmente o se expanden mediante adquisiciones: la inversión directa es posterior a una primera etapa de exportación "mercantilista". La diversificación tecnológica, los menores costos de producción, las habilidades de gestión y los productos o procesos innovadores son elementos que impulsan la internacionalización, paralelamente a las presiones competitivas en los mercados de origen y a otros factores de expulsión.

Sin embargo, en años recientes, la atención se ha centrado sobre todo en Rusia y, más aún, en las multinacionales emergentes de Asia. ${ }^{6}$ América Latina y las multilatinas han sido objeto de mucho menos interés. Son excepciones los estudios de Goldstein (2008) sobre el caso de la empresa brasileña de aeronáutica Embraer; Cuervo-Cazurra (2008), que ofrece un examen más general; Santiso (2006a); Alfaro y Hammel (2006); Baena (2002) sobre el caso de la empresa petrolera venezolana PDVSA; Kosacoff, Forteza y otros (2001) sobre el caso singular de Arcor, y Chudnovsky, Kosacoff y López (1999).

\section{III}

\section{Factores que impulsan el crecimiento de las multilatinas}

El presente artículo se centra en las multinacionales emergentes de tres países latinos cuya internacionalización fue impulsada por factores diferentes: España, Brasil y México. España es un caso específico que puede ser aleccionador como precedente. En Brasil, para las multinacionales de primer nivel, como Vale y la petrolera Petrobras, ha sido vital la dotación de recursos. La ventaja de México, en cambio, es su cercanía al enorme mercado interno de los Estados Unidos.

Sería una simplificación reducir el éxito de las multilatinas a la abundancia de recursos naturales y al bajo costo de la mano de obra. Van Agtmael (2007) destruyó recientemente estos mitos subrayando el alto grado de innovación característico de la gran mayoría de las principales multinacionales de mercados emergentes, incluidas las latinoamericanas. Solo un puñado de las 25 principales empresas emergentes del mundo que él identifica como tales se basan en recursos naturales o en mano de obra barata para obtener una ventaja competitiva. Basta señalar el nivel de vanguardia de la tecnología de reacción de la empresa aeronáutica Embraer, en Brasil, y la pionera logística de Cemex, en México, que predomina en el sector mundial del cemento merced a un sistema de posicionamiento global que le permite despachar a pedido camiones mezcladores a obras de construcción, como si fueran taxis que responden a llamadas. En tal sentido, las multinacionales de países emergentes, sean de Rusia, Asia, India o América Latina, con frecuencia han superado efectivamente a sus contrapartes de países desarrollados, gracias a tecnologías y modelos de gestión innovadores.

Por último, un factor decisivo de esta internacionalización fue la particular dinámica financiera de la última década. Entre 1980 y el 2005, el acceso de América Latina a los mercados internacionales de capital mejoró notablemente (Fostel y Kaminsky 2007).

\footnotetext{
${ }^{6}$ Cabe mencionar los estudios siguientes: Khanna (2008), Sauvant (2008), Rugman y Jing (2008), Deutsche Bank Research (2006 y 2008), Khanna y Yafeh (2007), Goldstein (2007), Boston Consulting Group (2007, 2006a y 2006b) y Beausang (2003).
} 
Diez años atrás, los factores tras la internacionalización de las multilatinas ya existían: el cambio fundamental ha sido el mayor acceso de esas empresas a los mercados de capital locales e internacionales. En un sistema financiero mundial de enorme liquidez, gracias a las bajas tasas de interés de los países de la OCDE y la afanosa búsqueda mundial de rendimientos, el costo del capital se desplomó para muchos países emergentes (respecto a América Latina, véase el gráfico 5), lo que dio por primera vez a las empresas de estos países acceso a un endeudamiento financiable, en condiciones relativamente comparables a las de sus contrapartes de la OCDE. Ello contribuyó enormemente a que se establecieran las mismas reglas de juego para todos, brindando así a las empresas emergentes la oportunidad de demostrar su valía.

Las empresas latinoamericanas, por lo tanto, pudieron recurrir a los mercados financieros locales e internacionales, factor clave de su internacionalización (Claessens y Schmukler, 2007). El aumento de las corrientes de inversión directa que provenían de países emergentes también es congruente con investigaciones anteriores: Levy-Yeyati, Panizza y Stein (2007) señalaron cómo los ciclos económicos y de las tasas de interés de los países desarrollados incidían en las corrientes de IED a los países en desarrollo. Agregando las corrientes de inversión extranjera directa en tres regiones de origen (los Estados Unidos, Europa y Japón), descubrieron que las mismas eran contracíclicas respecto de los ciclos del
PIB y las tasas de interés en las dos primeras, y acíclicas o moderadamente procíclicas en la tercera (Levy-Yeyati, Panizza y Stein, 2007).

$\mathrm{Al}$ disminuir los márgenes y las primas de riesgo -lo que facilitó el acceso a los mercados financieros internacionales a menor costo- la capitalización de mercado de las multinacionales emergentes se disparó, al igual que los mercados bursátiles emergentes en general. En 1981, el valor total de las acciones de los mercados emergentes era de 80.000 millones de dólares; menos que el valor bursátil de Samsung en el 2005. En los últimos 25 años, ese valor total superó los 5 billones de dólares. En 1988 había apenas 20 empresas de mercados emergentes con ventas de más de 1.000 millones de dólares; en el 2005 había 270 con ventas que superaban ese monto, y 38 con ventas de más de 10.000 millones. En el 2008, multilatinas como la brasileña Vale han alcanzado una capitalización de mercado de más de 100.000 millones de dólares.

Esta dimensión financiera también impulsa lo que podría denominarse la segunda etapa del proceso de internacionalización de las multinacionales emergentes, incluidas las latinoamericanas: la etapa de transición desde las ventas en el exterior a las adquisiciones en el exterior (gráfico 6). A diferencia de lo que sucedía antes, cuando se apuntaba a adquisiciones en otros mercados locales o emergentes (Rugman, 2007 y 2005), dichas empresas buscan ahora negocios en los principales mercados de la OCDE. Esta nueva etapa de

GRÁFICO 5

América Latina: inversiones directas en el exterior y márgenes de la región (Millones de dólares y porcentajes)

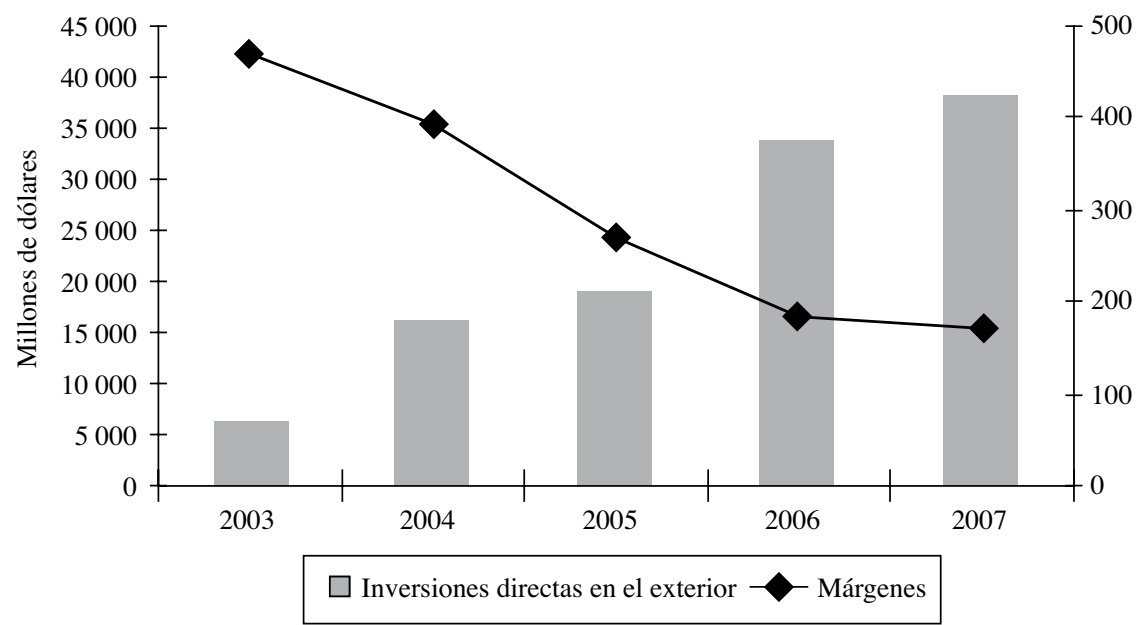

Fuente: OCDE (2007), sobre la base de Economist Intelligence Unit, índice de bonos de mercados emergentes (EMBI) de JP Morgan. 
GRÁFICO 6

América Latina: corrientes de inversiones directas al exterior ${ }^{a}$

(Miles de millones de dólares; principales economías latinoamericanas, excluyendo los centros financieros)

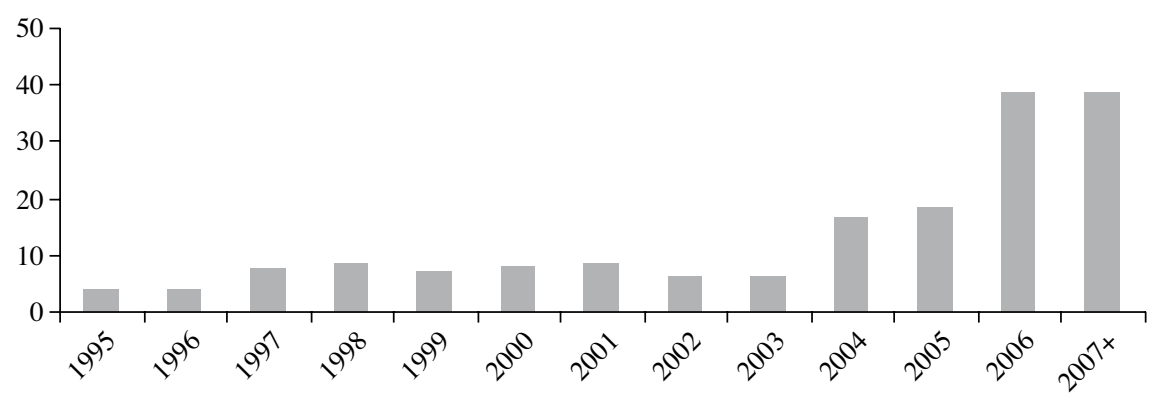

Fuente: OCDE (2007), sobre la base de Economist Intelligence Unit y Thomson Datastream.

a 2007+ es de enero a junio, incluidas las transacciones recientes. La adquisición de Rinker por Cemex (14.600 millones de dólares) fue parcialmente subvencionada por filiales, por lo cual no fue contabilizada en las cifras oficiales de inversión directa de México en el exterior en el 2007, pero, como el presente análisis aborda todo el efecto de las transnacionales latinas, aquí se contabiliza la cifra total.

su internacionalización les está acarreando cambios profundos en cuanto a escala y exposición geográfica, pero también en lo que toca a gobernanza empresarial. No solo han internacionalizado más la ubicación de sus plantas, sino que también cuentan con una mayor base de inversores extranjeros. La veloz evolución de los mercados financieros mundiales y latinoamericanos ayudó a estas compañías a transformarse en actores a nivel mundial. ${ }^{7} \mathrm{La}$ internacionalización de las empresas españolas tiene su reflejo en las empresas de América Latina: aunque entre unas y otras el proceso suele diferir, convergen en la dimensión financiera. Las empresas españolas, con el proceso de anclaje europeo, vieron disminuir sostenidamente el costo del capital en la década de $1990 .{ }^{8}$ En los años 2000, esta historia se repitió en América Latina, no gracias al proceso europeo, sino a una tendencia a la baja mucho más global, que llevó los márgenes y las primas de riesgo a mínimos sin precedentes en todos los mercados emergentes.

\section{IV}

\section{España: ex país emergente}

En el 2005, dos instituciones bancarias, el Banco Santander y el Banco Bilbao Vizcaya Argentaria (BBVA), desempeñaron un papel de liderazgo en la integración de la banca europea. Las iniciativas no surgieron de bancos alemanes o franceses, ni de bancos suizos o británicos, sino de la compra del Abbey National Bank de Gran Bretaña por el Santander Central Hispano de España, por 1.500 millones de euros, y del intento del BBVA de comprar el BNL italiano. Se sumó a esas

\footnotetext{
${ }^{7}$ Sobre esta transformación, véase Ananchotikul y Eichengreen (2008).
}

iniciativas la de ABN Amro y Unicredito, de realizar adquisiciones en Italia y Alemania, respectivamente. Los bancos españoles tomaron, pues, la delantera en el proceso de concentración del sector de la banca europea. En menos de 10 años, los bancos Santander y BBVA se habían transformado en actores principales de su sector, con capitalizaciones bursátiles que superaban las del Deutsche Bank o la Société Générale. Paralelamente, Telefónica avanzaba hacia una posición de liderazgo en

\footnotetext{
${ }^{8}$ Véase en Hardouvelis, Malliaropulos y Priestley (2007) un panorama general de los efectos de la Unión Económica y Monetaria sobre el costo del capital en la zona euro.
} 
su sector, consolidando su posición internacional con la compra del grupo de telefonía móvil británico O2 por la cifra sin precedentes de 26.000 millones de euros. En el 2008, Telefónica es una de las mayores empresas del mundo en su sector, compite con Verizon y Vodafone y exhibe una capitalización bursátil más importante que su contraparte alemana, Deutsche Telekom.

Todas estas adquisiciones e intentos de tomar el control de otras empresas derivan del auge de la economía española y de la globalización de sus empresas. En menos de dos décadas, España se ha transformado en ejemplo de un desarrollo económico dinámico: 20 años después de integrarse a la Unión Europea, pasó a ser la octava potencia económica mundial en términos de producto interno bruto (PIB). Actualmente, sus principales ciudades son de las más atractivas para establecer casas matrices de empresas multinacionales en Europa. También sorprende el prestigio adquirido por escuelas de negocios "made in Spain". En el 2006, la IESE Business School de la Universidad de Navarra quedó por segunda vez a la cabeza de la clasificación de escuelas de negocios creada por The Economist, adelante de las de Stanford, Chicago y Harvard. El mismo año, Esade, otra escuela de negocios con base en Barcelona, llegó al tope de la clasificación internacional que publica The Wall Street Journal. En los años siguientes se repitieron éxitos similares.

Una señal clara del reconocimiento internacional de los gerentes made in Spain es el creciente número de administradores españoles que se desempeñan en los directorios de algunas de las más grandes empresas europeas, como Siemens de Alemania, Carrefour de Francia o Nestlé de Suiza. En el 2006, Eduardo Montes ocupó un lugar en el directorio de Siemens, en tanto que José Luis Durán alcanzaba la máxima jerarquía de Carrefour. En Nestlé, nada menos que dos gerentes españoles están en el directorio de la empresa, en tanto que en Alstom, la región de Asia es administrada por un español.

Pero el cambio más espectacular tal vez sea el registrado dentro de las empresas españolas. Hace poco más de diez años, esas empresas estaban centradas en su mercado interno, con escasa o nula proyección o reconocimiento internacionales. Sin embargo, en menos de diez años media docena de ellas llegó a posiciones internacionales de primera línea (Santiso, 2007a y 2007b; Guillén, 2005). Hay empresas líderes españolas en todas las clasificaciones mundiales: el fondo de inversiones Fidelity International, uno de los mayores de la comunidad financiera, colocó a dos empresas españolas (Telefónica y Santander) en su lista del 2005 de las diez principales multinacionales europeas. España estaba, pues, a la par de Francia y superaba a Alemania (las empresas alemanas perdieron su lugar en la lista). Veinticinco años antes, en 1985, ni una sola empresa española figuraba en esa clasificación (en la que sí estaban, a esa altura, siete empresas alemanas). En apenas diez años, el empresariado español ha seguido una trayectoria meteórica.

Es interesante observar que los mercados emergentes, y en particular América Latina, desempeñaron un papel clave en esta evolución. Las grandes empresas españolas habían apostado muy fuerte en la región latinoamericana desde temprano: en 1999, en la cresta de la ola de inversiones en América Latina, 65\% de la inversión de las empresas españolas en el exterior se concentraba en la región. España es ahora el principal inversor extranjero directo en América Latina, por delante de los Estados Unidos. Hoy en día, las siete multinacionales más importantes del índice IBEX 35, que a mediados de 2006 representaban $60 \%$ del valor bursátil total español, generan casi $30 \%$ de su ingreso en América Latina. En el 2004, obtuvieron en la región 41.000 millones de dólares, es decir, el equivalente a 5,6\% del PIB de España. En el 2005 y el 2006, los dos principales bancos españoles acumularon utilidades comparables en América Latina y en España. De esta manera, las multinacionales españolas se transformaron, tal vez sorprendentemente, en las primeras multilatinas.

Realizamos un estudio sistemático de la presencia en América Latina de las principales empresas europeas que cotizan en bolsa. Como era de esperar, las empresas españolas son las de mayor presencia en términos de ventas. Algunas, como BBva o Telefónica Móviles, obtuvieron casi la mitad de sus ingresos del 2005 en América. En total, ocho de las 28 empresas europeas con mayores ventas en América Latina tienen base en España (solo dos empresas alemanas están en ese nivel). Como se indica en el gráfico 7, todas las empresas españolas subieron su apuesta en América Latina entre el 2004 y el 2005, en tanto que del grupo de empresas europeas de la OCDE con ventas en América Latina superiores al 10\% de sus ventas totales, algunas como Suez (de Francia), BG Group (del Reino Unido) u Holcim y Syngenta (ambas de Suiza), redujeron su exposición relativa en la región (gráficos 8 y 9).

La apuesta era un claro voto de confianza en América Latina y una acción sin precedentes desde el seno de Europa. Una empresa como Telefónica, por ejemplo (con la quinta capitalización de mercado de su sector a fines del 2005, por delante de France Telecom y Deutsche Telecom), invirtió la cifra récord de 75.000 millones de euros en América Latina entre 1990 y el 2006, con 
GRÁFICO 7

América Latina: presencia de las compañías europeas más importantes que efectúan $10 \%$ o más de sus ventas en la región, 2004 y 2005

(Porcentajes)

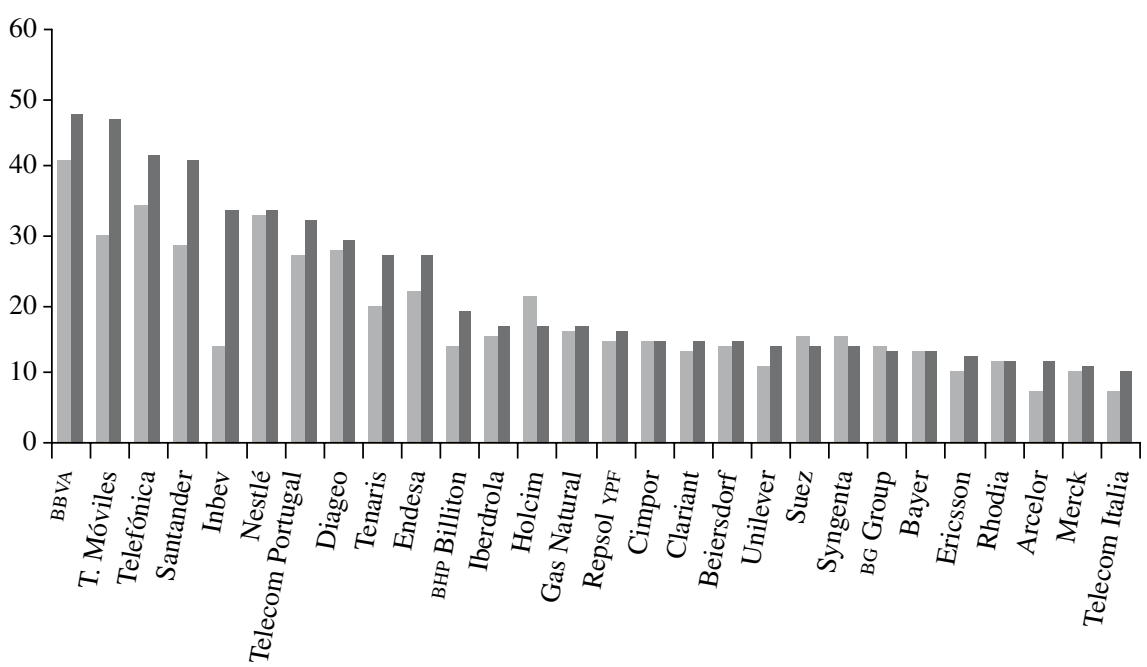

$\square$ Ventas en A.L. como \% de las ventas totales de la empresa, 2004

$\square$ Ventas en A.L. como \% de las ventas totales de la empresa, 2005

Fuente: elaboración propia sobre la base de informes anuales de las empresas, año 2006.

GRÁFICO 8

América Latina: presencia de las empresas europeas más importantes que efectúan entre $5 \%$ y $10 \%$ de sus ventas en la región (Porcentajes)

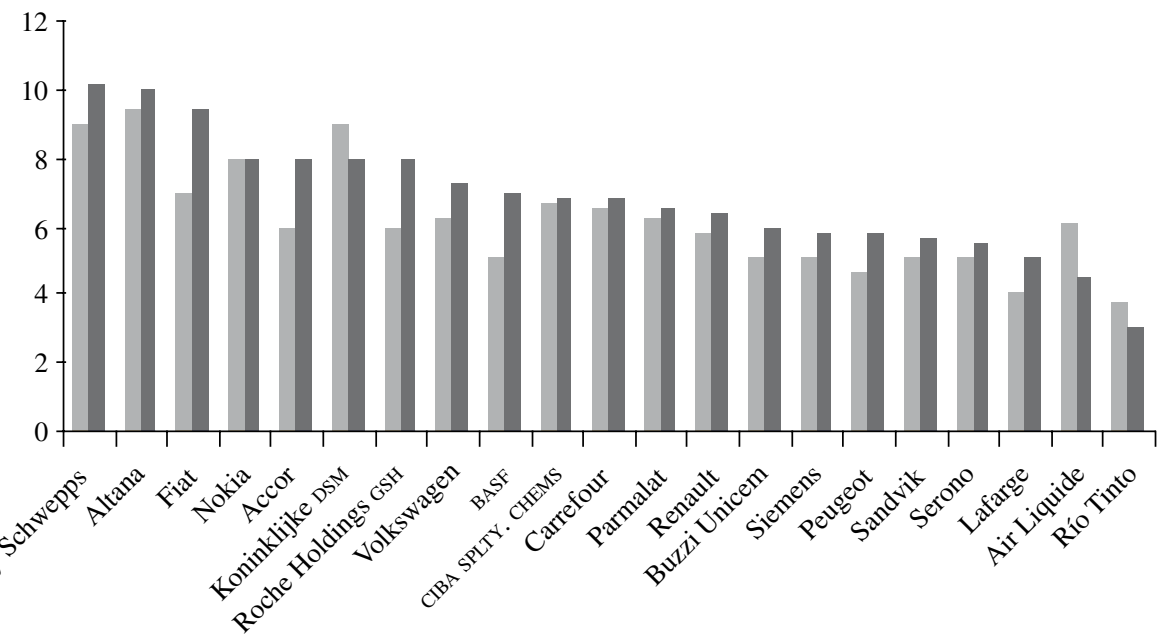

$\square$ Ventas en A.L. como \% de las ventas totales de la empresa, 2004

Ventas en A.L. como \% de las ventas totales de la empresa, 2005

Fuente: elaboración propia sobre la base de informes anuales de las empresas, año 2006. 


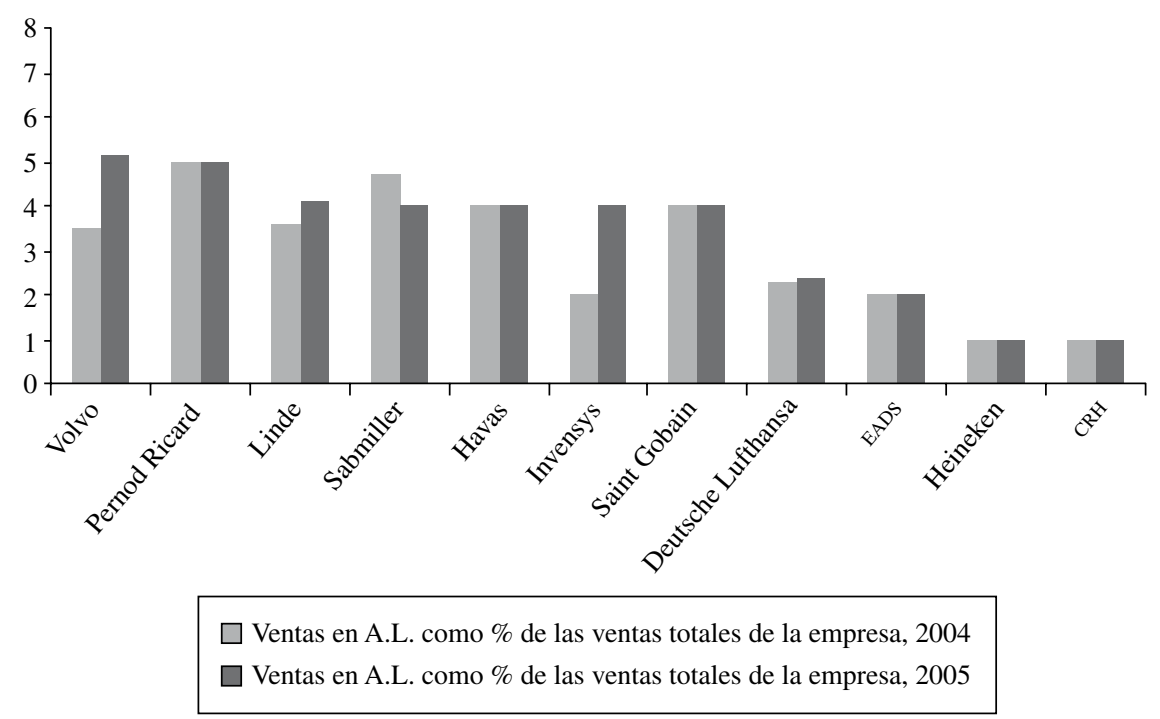

Fuente: elaboración propia sobre la base de informes anuales de las empresas, año 2006.

adquisiciones iniciales de 41.000 millones de euros e inversiones posteriores en infraestructura tecnológica por un total de 34.000 millones. En conjunto, esas cifras representaban casi $45 \%$ del total de IED neta de España en América Latina.

La visión de largo plazo de las empresas españolas quedó en claro poco después de la crisis argentina del 2001, cuando al retirarse un gran número de empresas norteamericanas y europeas, las multinacionales españolas capearon el temporal y apuntaron a nuevas oportunidades de inversión en el norte del continente americano, como las operaciones que estableció el BBVA en los Estados Unidos, México y Colombia.

Las claves del éxito de esta globalización latina son diversas, pero la capacidad de adaptación de sus plataformas tecnológicas, los procesos de fomento de negocios y los sistemas de riesgo fueron vitales. Resultaron valiosísimos elementos como los recursos humanos, el conocimiento adquirido por las empresas en mercados de ingreso medio (en el caso de España, durante algo más de un cuarto de siglo) y la capacidad de transferir y adaptar ese conocimiento al contexto latinoamericano.

A partir del 2005, las multinacionales españolas empezaron a prestar nuevamente atención a los países desarrollados, con lo que el grueso de la IED se canalizó hacia países de la OCDE: en el 2005, solo 15\% de la IED española se dirigía a América. La mayoría de las multinacionales españolas completaron su expansión latinoamericana. Con pocos espacios que llenar en América, las empresas españolas procuraron diversificarse hacia otras regiones. Telefónica miró otra vez a Europa -incluida Europa oriental- y a Marruecos y China. Los bancos también reorientaron su atención a Europa, Asia y a posibles interacciones de los Estados Unidos y América Latina. Empresas de sectores como la electricidad, el petróleo y la infraestructura procuraron consolidar su presencia más allá de América: Ferrovial y Abertis (infraestructura) tomaron respectivamente el control del grupo BBA (British Aviation and Materials) y de la italiana Autostrade.

La veloz transformación de la economía española y de sus empresas testimonia arrojo, gran capacidad de innovación y entusiasmo por operar en mercados lejanos. Toda una generación de empresarios se lanzó a esta aventura y pudo transformar a sus empresas en líderes mundiales. El gigante Inditex es hoy una de las más poderosas empresas multinacionales del sector textil, junto a GAP (Estados Unidos), Hennes \& Mauritz (H\&M, Suecia) y Benetton (Italia). Está presente en más de 55 países y el 55\% de sus ventas se realiza en el exterior. Su modelo de negocios es un paradigma en las principales escuelas de negocios, como la de Harvard.

Una empresa como Telefónica se transformó en multinacional con operaciones en 17 países y presencia en más de 40 y sigue siendo el mayor inversor en América Latina, 
con cerca de 100.000 millones de euros en adquisiciones internacionales e inversiones en infraestructura entre 1990 y el 2006. A mediados del 2005, Telefónica tenía 56\% de sus clientes fuera de España, los que generaban 33\% del ingreso del grupo, y era la empresa líder en América Latina, con un $25 \%$ del mercado en el sector de la telefonía fija y móvil y $58 \%$ de su personal total destacado en esa zona geográfica. A mediados del 2005 (antes del surgimiento de O2), con 145 millones de clientes, la empresa ya era el cuarto operador del mundo de su sector en términos de clientes administrados y capitalización mundial. La aventajaban únicamente Vodafone, Verizon y China Mobile (siendo que en 1999 apenas estaba entre los primeros 20) y la seguían Deutsche Telekom o France Telecom. En términos de capitalización bursátil, Telefónica es casi tres veces más poderosa que una empresa como Danone y dos veces y media mayor que empresas como Philips o Sony. También vale la pena señalar su contribución al desarrollo económico de los países en que ha invertido: el ingreso local de Telefónica equivale a un promedio de 1,8\% del PIB de los principales países en que opera (por ejemplo, 2,3\% del PIB de España y Perú y 1,8\% del PIB de Chile), y emplea a 110.000 personas en América Latina (de las 190.000 que empleaba a nivel mundial a mediados del 2005). En el año 2005, Telefónica era el segundo mayor contribuyente en Brasil (pagaba 2.830 millones de dólares), detrás de Petrobras, y el cuarto empleador del país (con 44.000 empleados), después del servicio de correos y de empresas minoristas como Pão de Azúcar y Carrefour.

En el sector de la energía, multinacionales españolas como Endesa, Unión Fenosa, Iberdrola, Gas Natural y Repsol YPF han venido expandiendo sostenidamente sus operaciones internacionales. Endesa, líder en el país en servicios de electricidad, ha alcanzado una presencia internacional apreciable, en especial en América Latina, pero también en Europa (Italia, Francia y Portugal). En cuanto a Unión Fenosa, su ingreso internacional equivale a un tercio de su ingreso total y la empresa está presente a través de su subsidiaria Soluziona en casi 30 países (la mitad de ellos en América Latina). Unión Fenosa Internacional tiene presencia en diez países de cuatro continentes. Iberdrola, la número uno española en términos de capacidad instalada y líder mundial en energía eólica, también ha logrado una importante presencia mundial, actualmente con actividades en energía e ingeniería en 35 países. En diciembre del 2005, la empresa seguía apostando a su globalización con la firma de un importante acuerdo internacional con la empresa argelina Sonatrach, por 10.000 millones de euros a lo largo de 20 años, para emprendimientos conjuntos. Repsol YPF está ahora en 30 países y ha invertido más de 30.000 millones de euros entre 1995 y el 2005 (equivalente a 65\% de su inversión total), lo que la transforma en uno de los mayores inversores extranjeros en la región en los últimos diez años. Finalmente, Gas Natural, otra de las grandes empresas del sector energético, también ha desarrollado una intensa actividad internacional en los últimos años. Tiene a la mitad de su fuerza laboral destacada en el exterior, con presencia en América Latina (Argentina, Brasil, México, Colombia y Puerto Rico), Italia y Marruecos.

En el sector de la banca, Santander y bBva son emblemáticos de esta exitosa estrategia de globalización en América. El BBVA, por ejemplo, no era mucho más que un banco nacional minorista en 1995, con escasa presencia en el extranjero. En apenas diez años, se ha transformado en un banco universal, internacional, presente en tres continentes en todas las áreas mayoristas y minoristas de la actividad bancaria, incluida la gestión de activos, pensiones y seguros. En ese período invirtió más de 13.500 millones de euros en América Latina. En el 2006, el banco estaba presente en 35 países (14 de ellos latinoamericanos) y ostenta 50 nacionalidades diferentes entre los 100.000 empleados del grupo en distintas partes del mundo. Asimismo, está por completar sus arreglos de licencias en Asia para posicionarse ante el auge de la inversión y el comercio entre Asia y América Latina, impulsado por el poderoso surgimiento de China e India. ${ }^{9}$ En noviembre del 2006, el BBva pagó 1.000 millones de euros por acciones en bancos chinos controlados por el conglomerado Citic, respaldado por Beijing, con el propósito de ingresar al pujante sector financiero de China y perfilarse mejor como líder de la intermediación entre China y América Latina. Fue la mayor inversión de todos los tiempos de un operador español en China, y siguió a la de Telefónica. De hecho, representó una de las mayores capitalizaciones bancarias de Europa, por encima del Deutsche Bank y de la Société Générale, mientras que su rival, Santander, realizó en el 2006 la mayor capitalización europea cuando tomó el control de Abbey National. Estos dos bancos -el BBVA y el Santander- pasaron a ser los más rentables y eficientes de la zona euro y su presencia en los mercados emergentes los ayudó a elevar tanto sus ingresos como su capitalización de mercado. Por el contrario, el Commerzank, apoyado casi únicamente en el mercado europeo, tuvo resultados muy deficientes.

\footnotetext{
${ }^{9}$ Véase más detalles sobre el impacto de China en América Latina en el trabajo del Centro de Desarrollo de la oCDE (Blázquez, Rodríguez y Santiso, 2006).
} 


\section{V \\ Brasil y México: una nueva generación de multilatinas}

Se pasará ahora a otro continente y otros países latinos, porque la historia de la globalización también se escribe en América Latina. Una serie de empresas de países latinoamericanos son ejemplos notables: en Argentina, por ejemplo, Arcor es actualmente líder mundial en la fabricación de golosinas y el primer exportador de confituras de Argentina, Brasil y Chile, con presencia en 117 países de los cinco continentes; los fabricantes de tuberías Tenaris tienen presencia en Argentina, Brasil, México y la República Bolivariana de Venezuela, al igual que en
Canadá, Italia y Japón (en el 2005, esta empresa concretó más de $85 \%$ de sus ventas fuera de América Latina).

Pero las mayores multilatinas emergentes son mexicanas y brasileñas: 85 de las 100 empresas de primera línea de la región y 35 de las 50 más rentables son originarias de estos dos países (cuadro 2). En menos de diez años, las empresas mexicanas multiplicaron sus fusiones y adquisiciones. El total de sus inversiones fuera de México asciende a más de 25.000 millones de dólares, superando los 20.000 millones de dólares de sus pares brasileñas (gráfico 10). México y Brasil

CUADRO 2

América Latina: las diez mayores multinacionales latinoamericanas no financieras

\begin{tabular}{|c|c|c|c|c|c|c|}
\hline \multirow[t]{2}{*}{ Empresa } & \multirow[t]{2}{*}{ País de origen } & \multirow[t]{2}{*}{ Sector } & \multicolumn{2}{|c|}{$\begin{array}{l}\text { Activos, fines de } 2006 \\
\text { (millones de dólares) }\end{array}$} & \multicolumn{2}{|c|}{$\begin{array}{l}\text { Ventas, fines de } 2006 \\
\text { (millones de dólares) }\end{array}$} \\
\hline & & & Extranjeros & Total & Extranjeros & Total \\
\hline CEMEX S.A. & México & Construcción & 24908 & 29972 & 14551 & 18249 \\
\hline Vale do Rio Doce (Vale) & Brasil & Minería & 24382 & 60954 & 16145 & 20363 \\
\hline América Móvil & México & Telecomunicaciones & 10662 & 29473 & 9618 & 21526 \\
\hline Telmex & Mexico & Telecomunicaciones & 10625 & 44532 & 4362 & 16115 \\
\hline Petrobras & Brasil & Petróleo expl./refin./distr. & 9953 & 98680 & 23160 & 93893 \\
\hline Petróleos de Venezuela ${ }^{\mathrm{a}}$ & R.B. deVenezuela & Petróleo expl./refin./distr. & 8868 & 55355 & 25551 & 46589 \\
\hline Gerdau & Brasil & Metales y productos metálicos & 4926 & 12595 & 6474 & 10940 \\
\hline FEMSA - Fomento Económico Mexicano & México & Alimentos y bebidas & 3455 & 13463 & 2854 & 11707 \\
\hline Gruma & México & Alimentos y bebidas & 1486 & 2784 & 1937 & 2823 \\
\hline Grupo Bimbo & México & Alimentos y bebidas & 1386 & 3851 & 1892 & 5859 \\
\hline
\end{tabular}

Fuente: OCDE (2007), informes anuales de las empresas y UNCTAD (2006).

a Los datos de PDVSA (Petróleos de Venezuela) son de 2004.

GRÁFICO 10

Brasil y México: inversión directa en el exterior (Millones de dólares)

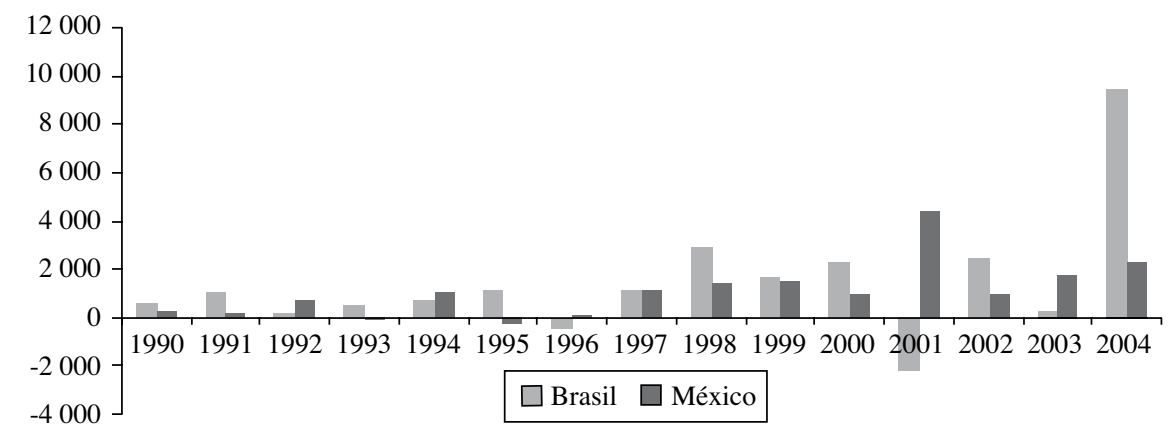

Fuente: elaboración propia sobre la base de UNCTAD (2006). 
encabezan el proceso de inversiones directas en el exterior: en el 2004, las empresas latinoamericanas en conjunto invirtieron 22.000 millones de dólares allende sus fronteras, lo que representó un salto de 500\% respecto al año anterior. El incremento más espectacular lo protagonizó Brasil. De acuerdo con datos de la UNCTAD, las empresas brasileñas invirtieron casi 10.000 millones de dólares fuera de su país en el 2004, en comparación con apenas 250 millones el año anterior. En el 2005, el total de inversión directa brasileña en el exterior llegó a más de 71.000 millones de dólares, superando con creces los 28.000 millones de dólares de México y los 22.000 millones de dólares de Argentina (y casi el mismo monto de Chile), con lo que Brasil se forjó la posición más sólida de América Latina en inversiones directas en el exterior: el país genera $40 \%$ del acervo total de inversiones directas de la región en el exterior. En el 2006, según datos de CEPAL (2008), la inversión directa en el exterior de la región anotó un nuevo récord (42.000 millones de dólares) que duplicó los montos invertidos en el exterior tanto en el 2005 como en el 2007.

Una fuerza motriz fundamental de esta nueva ola de internacionalización ya no fue, como en décadas anteriores, solamente la presión competitiva en los mercados internos o los factores de atracción relacionados con la expansión y diversificación de las ventas, los mercados y las bases de producción. También es clave la dimensión financiera: todas estas empresas registraron aumentos de su capitalización de mercado y de su capacidad para acceder a los mercados de capital locales e internacionales a menores costos. Empresas como Cemex o Vale pueden ahora llegar a los mercados financieros en las mismas condiciones que sus competidores de la OCDE.

La nueva ola de internacionalización también trajo consigo enormes aumentos de las ventas en el exterior.
Sobre la base de la clasificación de la revista América Economía de las 100 principales empresas latinoamericanas, se calculó qué porcentaje de las ventas totales de las empresas correspondía a ventas en el exterior. Para las empresas peruanas y chilenas de la lista, las ventas en el exterior representaron en el 2005 no menos de $70 \%$ de sus ventas totales (gráfico 11). Pero inclusive para países como Brasil y México, con muchas más empresas en la lista, los promedios eran impresionantes: en el caso de las empresas mexicanas, $47 \%$ de sus ventas totales se efectuaba en el exterior (sobre todo dirigidas a los Estados Unidos) y en el caso de sus contrapartes brasileñas, la cifra era de $39 \%$. El grueso de todas las exportaciones (75\%) se vinculaba a la exportación de petróleo, gas y minerales (gráfico 12), lo que no sorprende, en una región en que más de un tercio de sus exportaciones se relaciona con productos básicos.

Para entender este proceso es necesario tener en cuenta que el entorno en que evolucionaron las empresas mexicanas y brasileñas fue transformado por el ingreso masivo de fuertes competidores extranjeros en los últimos diez años (algunos de ellos españoles, como ya se vio). En consecuencia, entre 1991 y el 2001 el perfil de las 500 empresas más importantes establecidas en América Latina cambió radicalmente. El número de empresas estatales disminuyó muchísimo, de 20\% en 1991 a menos de 9\% diez años después. En el mismo período, las empresas multinacionales extranjeras marcaron territorio ampliamente en la región: en 1991 representaban $27 \%$ de las 500 empresas más importantes y en el 2001 habían aumentado a 39\%. La creciente competencia puso presión sobre los grupos nacionales, que tradicionalmente suministraban productos y servicios a sus mercados locales. Las empresas más dinámicas apuntaron a los mercados externos

GRÁFICO 11

América Latina: exportaciones como proporción de las ventas locales de las 100 empresas latinoamericanas más importantes, 2006 (Porcentajes)

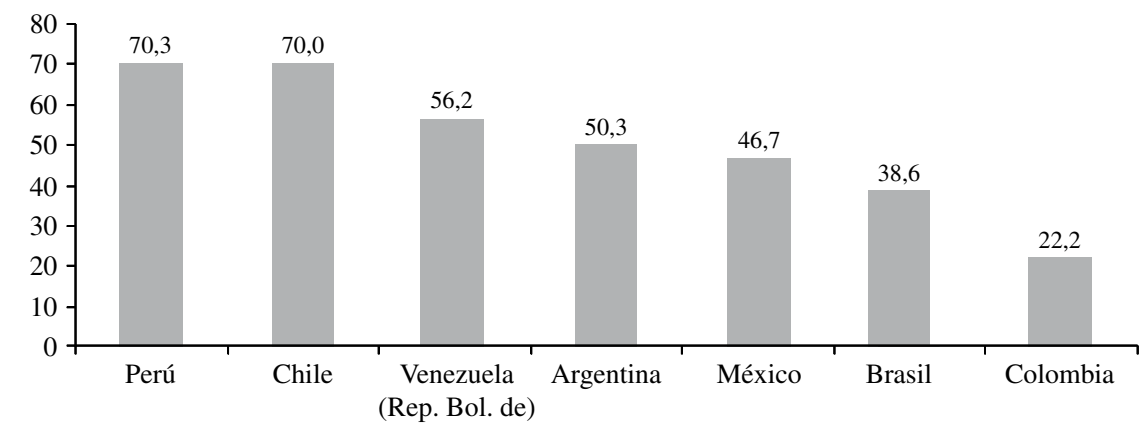

Fuente: datos de América Economía, varios números del año 2006. 
GRÁFICO 12
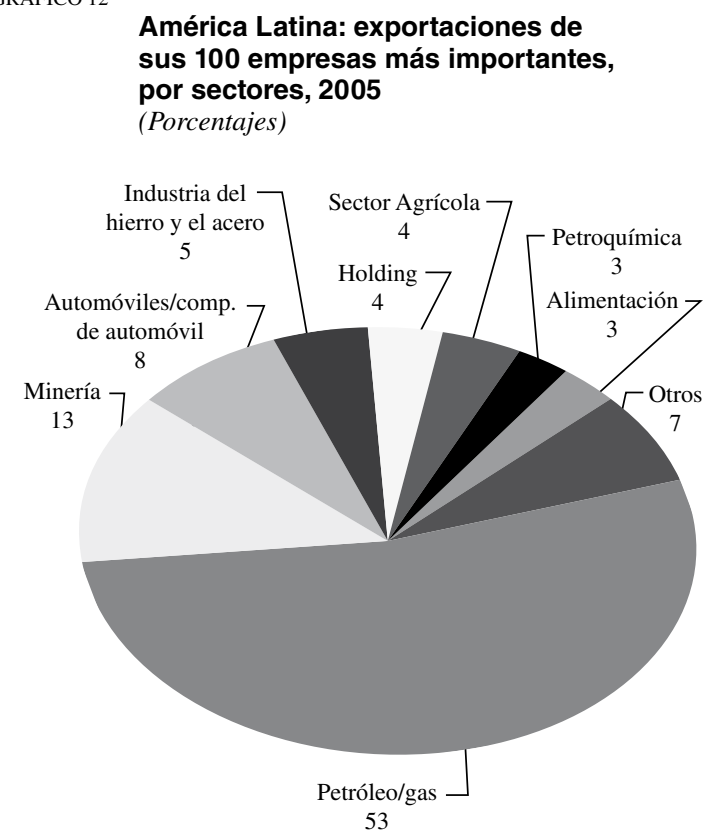

Fuente: datos de América Economía, varios números del año 2006.

y se convirtieron en multilatinas. Algunas orientaron su expansión a determinadas zonas de América Latina, concentrándose en el Mercosur o en la zona andina. Otras emprendieron una estrategia continental y algunas inclusive saltaron a mercados emergentes de otros continentes, como África y Asia, o a países de la OCDE, en particular los Estados Unidos.

Como se mencionó antes, este proceso se vio facilitado por las propicias condiciones financieras internacionales que empujaron a la baja el costo del capital en el mundo emergente y, en particular, en América Latina. Con esto mejoró el acceso de la región a mercados financieros internacionales, en tanto que sus mercados y capitalizaciones locales se desarrollaron en forma extraordinaria. A raíz de su repentino acceso al capital, las empresas latinoamericanas multiplicaron sus adquisiciones en sus mercados de origen y sobre todo en el exterior, tanto en América Latina como en otros mercados emergentes o de la OCDE. Esto incluyó operaciones en el mercado interno, ya que a comienzos de este siglo las adquisiciones en América Latina efectuadas por empresas latinoamericanas alcanzaron los 110.000 millones de dólares (gráfico 13). De esta cifra, más de 23.000 millones de dólares terminaron en países de la región que no eran los de origen de las empresas. En este proceso, como muestra el gráfico, las empresas más activas fueron las de Brasil y México.
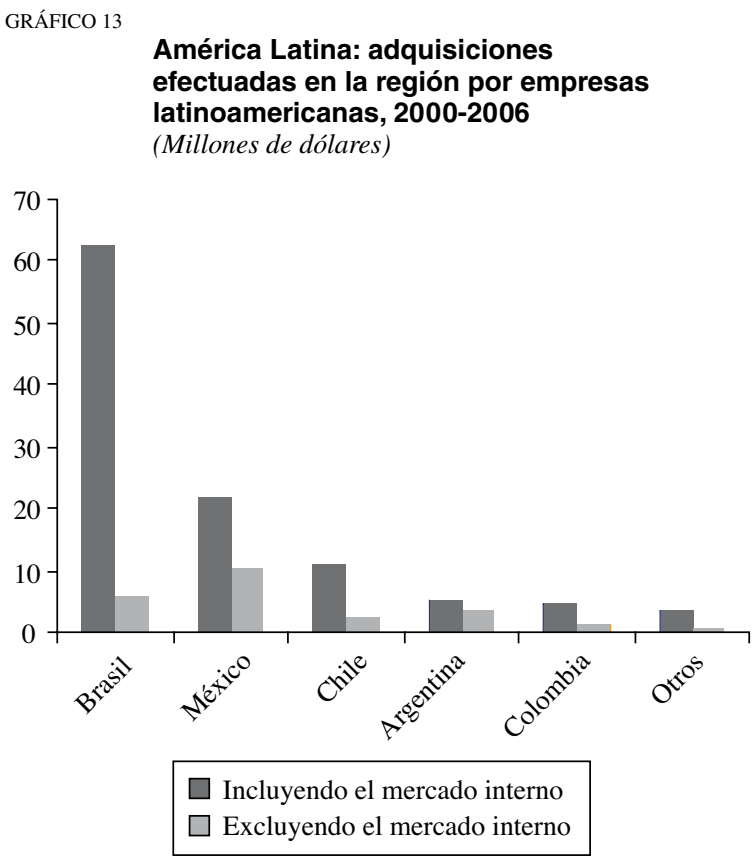

Fuente: datos del BвvA sobre finanzas empresariales, 2006.

México fue líder incuestionable en este proceso, con firmas pioneras como Cemex, cuya expansión mundial es, sin duda, uno de los casos más extraordinarios de éxito de la región. De 1990 al 2006, Cemex se transformó en líder mundial entre las multinacionales emergentes en términos de adquisiciones en el exterior, con no menos de 40 operaciones en ese período. En el 2006, apenas diez años después de su despegue internacional, Cemex tenía presencia en cuatro continentes, más de 15.000 millones de dólares invertidos en el exterior y sucursales no solo en América Latina sino también en los Estados Unidos, el Reino Unido, España, Egipto, Indonesia y Filipinas. En el 2005 concretó una de las transacciones más importantes jamás realizada por una compañía latinoamericana, con la adquisición de la RMC británica por cerca de 6.000 millones de dólares. Con esta compra, las ventas de Cemex en México bajaron a $21 \%$ de sus ventas totales, siendo mayores las ventas en Estados Unidos (27\%) y mucho más aquellas en Europa, que en el 2005 constituía el mayor mercado de Cemex y representaba casi $40 \%$ de sus ventas totales (España absorbía 10\% y el Reino Unido otro 10\%). Un año después de la adquisición en el Reino Unido, Cemex repitió su apuesta internacional al adquirir en 14.000 millones de dólares la empresa Rinker, el grupo australiano de materiales de construcción, con lo cual se convirtió en líder mundial del sector. Esta fue también 
la mayor adquisición concretada hasta la fecha en el sector de los materiales de construcción, superando los 9.500 millones de dólares que pagó Lafarge por Blue Circle en el 2001.

Estas inversiones en el exterior sacaron a luz otro aspecto de la globalización de la economía mexicana. México no solo registra una de las mayores tasas de apertura comercial entre los países emergentes (con ventas internacionales sobre todo en los Estados Unidos), sino que muchas empresas de ese país han optado por una presencia más directa en otros mercados, con establecimientos o adquisiciones muy importantes. El conglomerado Alfa, con base en Monterrey, ha establecido sociedades y alianzas estratégicas con más de 20 empresas de los Estados Unidos, Japón, Europa, Sudáfrica y México, todas ellas a la vanguardia de sus respectivos campos de acción.

El gigante de las telecomunicaciones Telmex se ha transformado en uno de los mayores competidores de la telefonía en América Latina. Junto con su vástago América Móvil, multiplicó las adquisiciones en la región, concluyendo su plan de expansión en solo dos años. En el 2005, América Móvil seguía concediendo licencias en la región. En sociedad con Bell Canada Inc. y SBC International, creó Telecom Americas como principal vehículo de expansión en América Latina. América Móvil cuenta hoy con sucursales e inversiones conjuntas en el sector de telecomunicaciones de Guatemala, Ecuador, Argentina, Brasil, Colombia, República Bolivariana de Venezuela, Estados Unidos, Puerto Rico, México y España. Otras empresas también sobresalen en otros sectores por su actividad internacional, como el grupo cervecero Modelo, activo en más de 150 países. El grupo Bimbo, fundado en 1945 en el sector agroindustrial, sigue destacándose y da ocupación a más de 80.000 personas; en los últimos años concretó un gran número de adquisiciones importantes en los Estados Unidos, donde en el 2005 efectuó casi 30\% de sus ventas netas.

Las compañías mexicanas han ingresado entonces en una nueva etapa de expansión que apunta a una presencia directa en el exterior, completa la etapa anterior y está vinculada a las crecientes ventas externas. Según las bases de datos y las clasificaciones de América Economía, algunos de los principales exportadores mexicanos están alcanzando niveles significativos de ventas en el exterior (gráficos 14 y 15). Para grupos como Nemak o Mabe las

GRÁFICO 14

México: principales exportadores, 2005

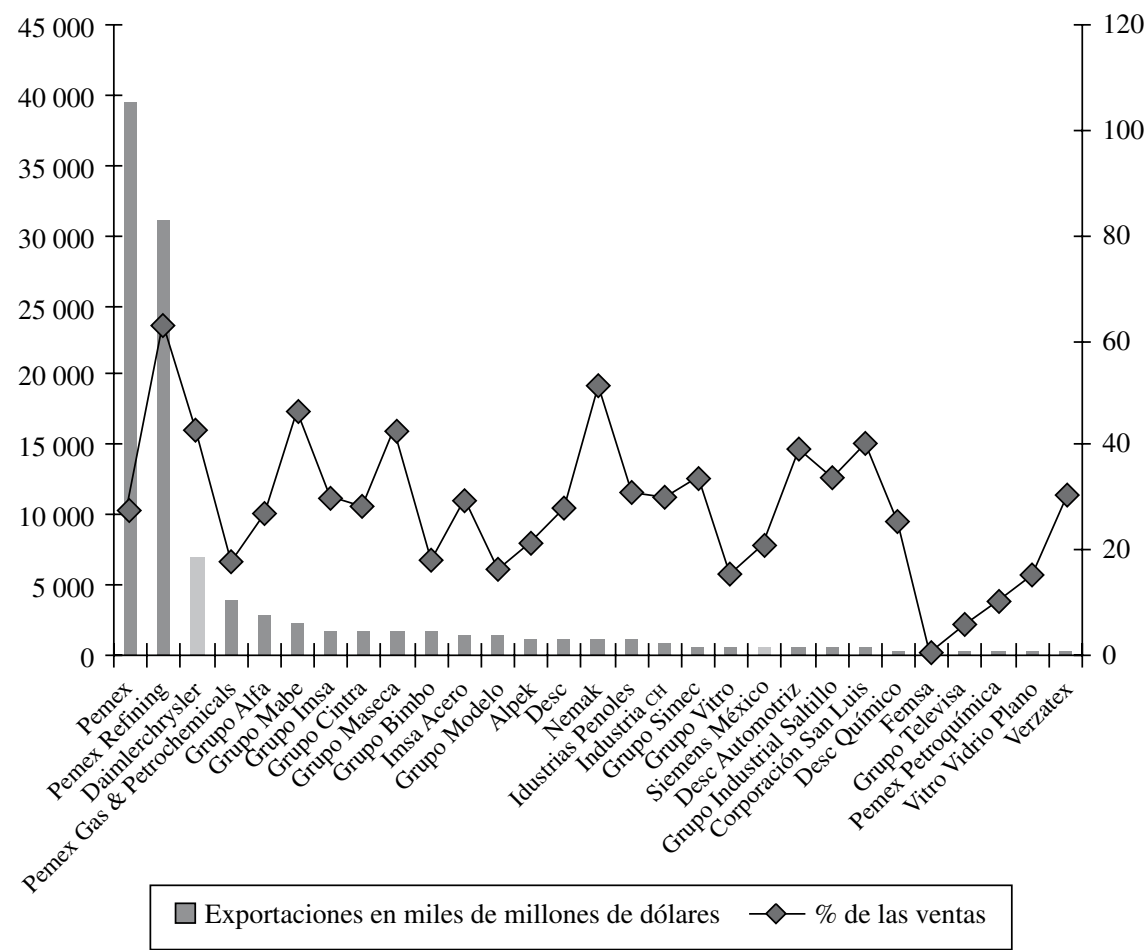

Fuente: elaboración propia sobre la base de varios números de América Economía del año 2006. 
GRÁFICO 15

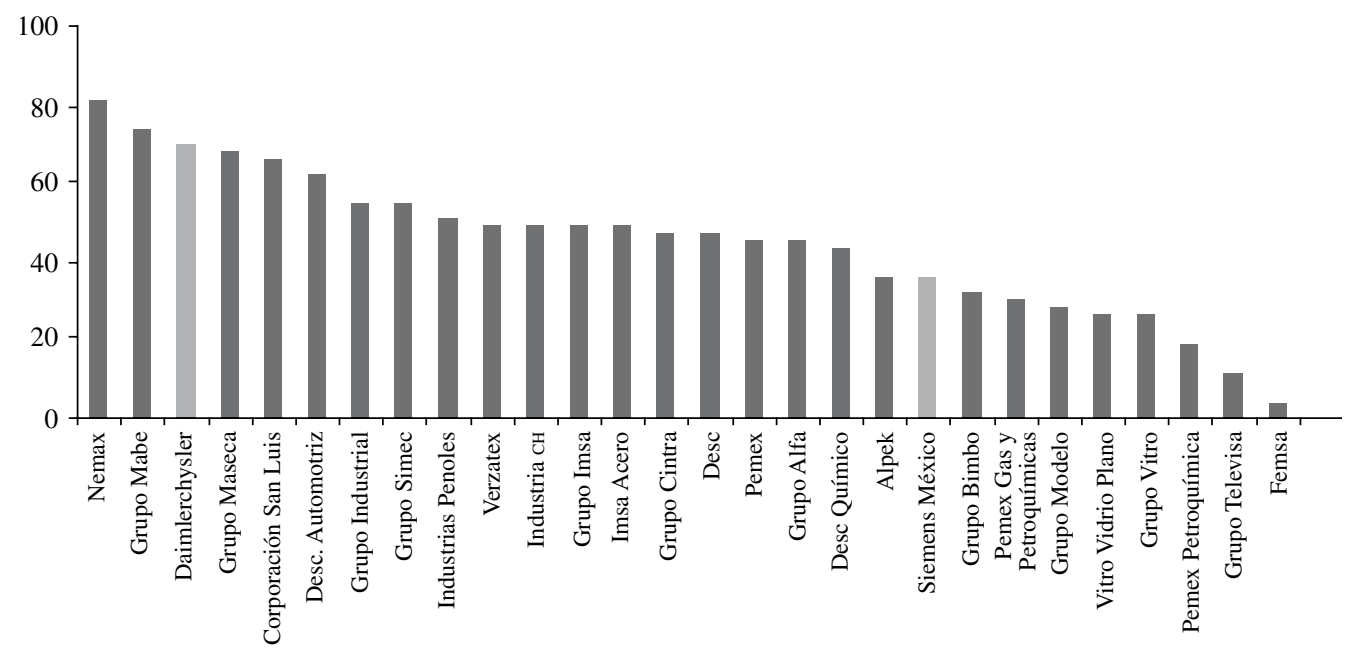

Fuente: elaboración propia sobre la base de varios números de América Economía del año 2006.

GRÁFICO 16

Brasil: principales empresas, 2005

(Ventas en el exterior como porcentaje de sus ventas totales)

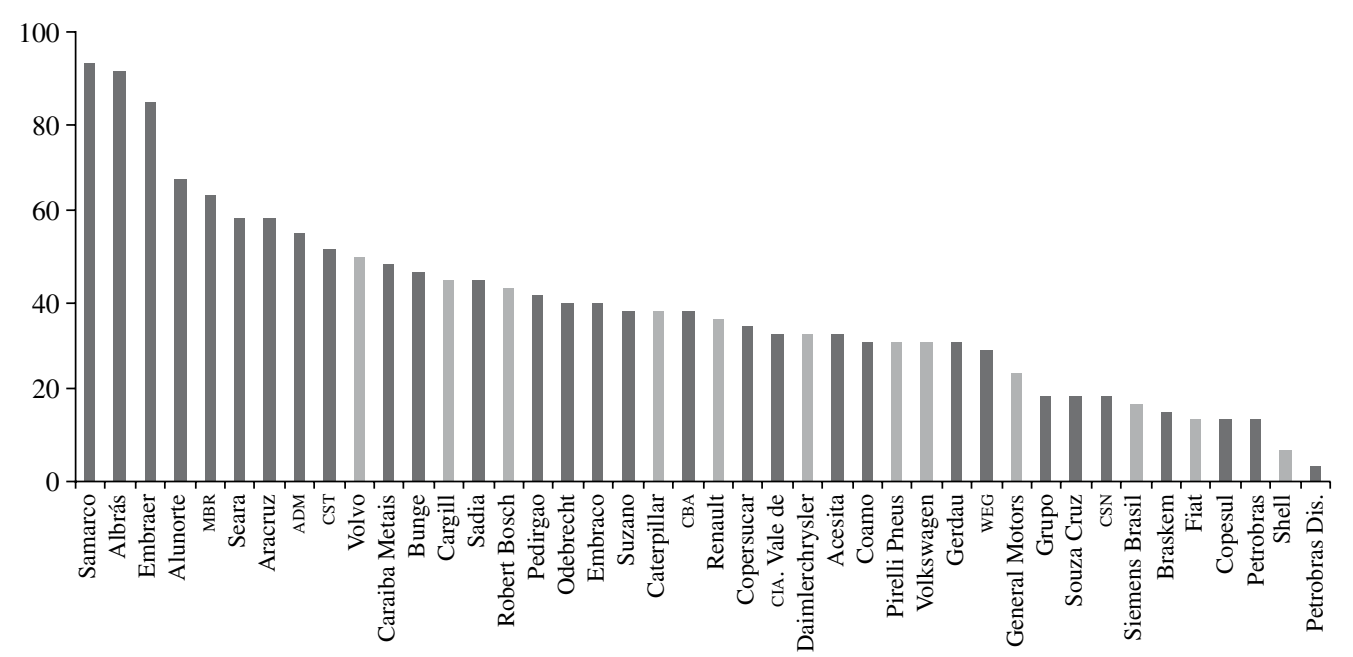

Fuente: elaboración propia sobre la base de varios números de América Economía del año 2006.

ventas internacionales representaron en el 2005, respectivamente, $82 \%$ y $69 \%$ de sus ventas totales. Es interesante comprobar que algunas empresas alemanas se encuentran también entre los principales exportadores establecidos en México: DaimlerChrysler y Siemens exportan, respectivamente, $69 \%$ y $35 \%$ de lo que producen en México.

En Brasil, los grupos más importantes también están avanzando a una segunda etapa en el escenario de globalización. En los últimos años se observó un aumento considerable del volumen de sus ventas fuera del país. Como en México, algunos de los principales exportadores de Brasil son empresas extranjeras, como Volvo, de Suecia, que vende en el exterior casi 50\% de su producción brasileña; General Motors, Cargill y Caterpillar, estadounidenses; Fiat y Pirelli, de Italia; Renault, de Francia, y Bosch y Volkswagen, de Alemania (gráfico 16). 
En el 2005, el grupo aeronáutico Embraer realizó $84 \%$ de sus ventas en el exterior, mientras que Aracruz Celulose, otro exportador líder del país que vende más de $60 \%$ de su producción exportada fuera de América Latina, efectuó sus ventas esencialmente en Europa, Norteamérica y Asia. En el sector del acero, Gerdau realizó $31 \%$ de sus ventas fuera de Brasil y la cifra correspondiente para Vale, la empresa que lidera el sector minero, fue de $33 \%$. Inclusive la petrolera Petrobras se convirtió en un gran exportador, llegando a efectuar en el exterior el $11 \%$ de sus ventas totales, tras iniciar operaciones de exploración y producción en los Estados Unidos, México, la República Bolivariana de Venezuela, Colombia, Ecuador, Perú, Bolivia, Nigeria y Angola. El sector de la agroindustria, uno de los más dinámicos del país, cuenta con una serie de grupos muy pujantes, como Sadia, que exporta a más de 65 países, incluidos Rusia, Japón y países del Medio Oriente, y factura casi la mitad de sus ventas en el extranjero (44\%). Al igual que Sadia, otros grupos están incrementando y diversificando sus exportaciones con éxito. Es el caso de la petroquímica Braskem: el $20 \%$ de sus exportaciones va a Europa y América Latina y el 50\% a Norteamérica (gráfico 17).

Sin embargo, todos estos grupos - yendo más allá de la etapa "mercantilista" - apuntan también a sustanciales operaciones de inversión en el exterior. Las estrategias reflejan dos objetivos de vasto alcance. Como la pionera Cemex, los grupos procuran, por un lado, ampliar sus mercados de operaciones, posicionándose en

GRÁFICO 17

Brasil: principales exportadores, 2005

(Ventas en el exterior como porcentaje de sus ventas totales)

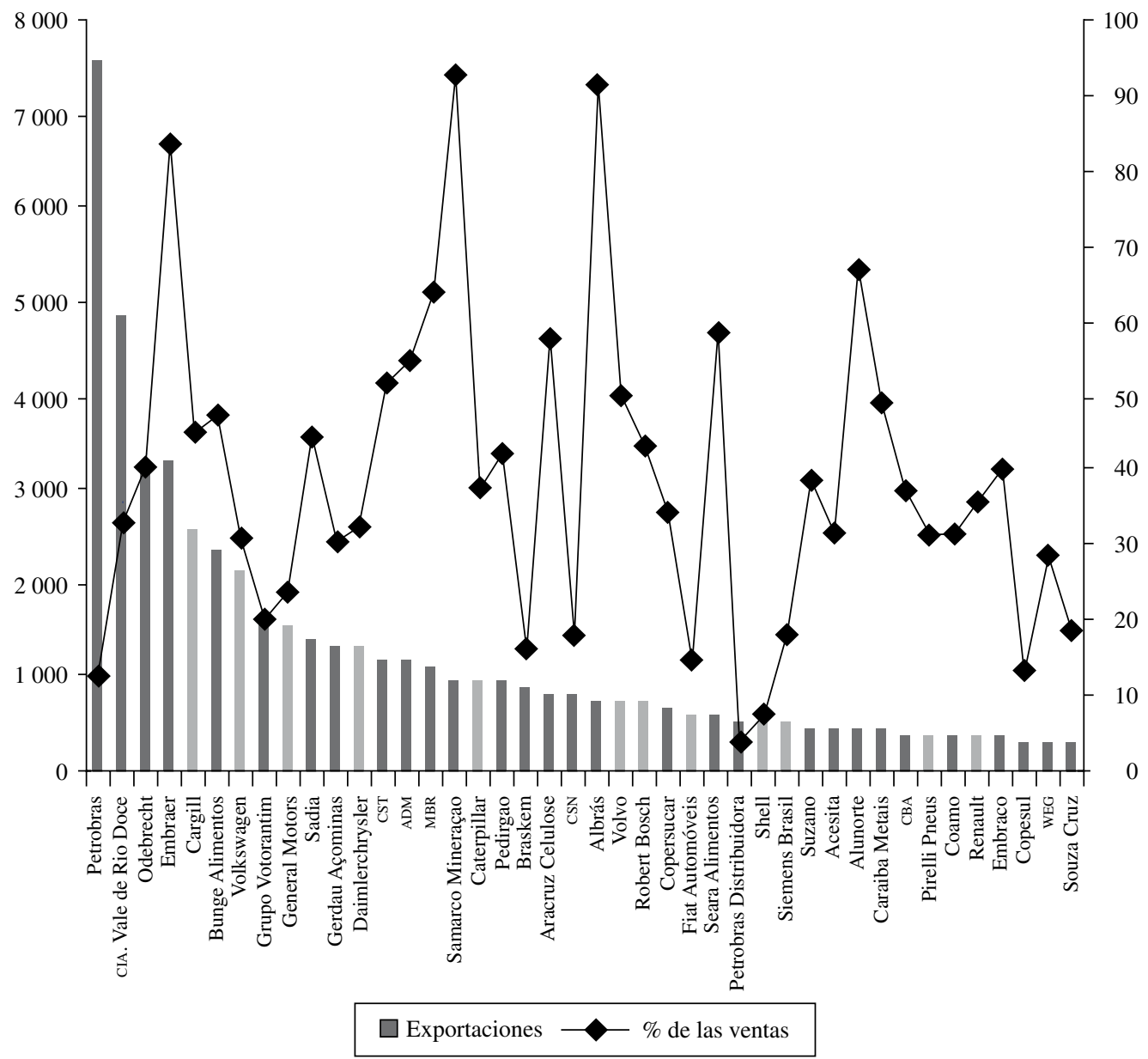

Fuente: elaboración propia sobre la base de varios números de América Economía del año 2006. 
otros países emergentes, sobre todo de América Latina; por otro, desde una perspectiva más estratégica, tratan de asentarse en países de la OCDE o subir su nivel de inversión para mejorar no solo su perfil industrial, sino también el financiero, y así reducir más sus costos de capital.

En el 2005, la productora de acero Gerdau siguió este camino, acumulando adquisiciones y comprando $40 \%$ de la española Sidenor a fines del año. La centenaria Gerdau logró posiciones importantes, no solo en América Latina (Brasil, Chile, Argentina, Colombia y Uruguay), sino también en Norteamérica (los Estados Unidos y Canadá), con lo que mejoró su perfil industrial y financiero. En el sector de transporte y equipos, Marco Polo, líder de Brasil en autobuses, también emprendió el camino hacia una presencia mundial. Con un ingreso internacional que representa la mitad de su ingreso total, la empresa cuenta ahora con plantas manufactureras no solo en Brasil, sino también en Argentina, Colombia, México, Portugal y Sudáfrica, y exporta a más de 60 países, entre ellos Francia, el Reino Unido, Alemania, España, Portugal, los Países Bajos, México, Argentina y Arabia Saudita.

Hay otros ejemplos prominentes entre conglomerados brasileños como Votorantim y el gigante minero Vale. Votorantim, una de las mayores empresas de América Latina, inició su inversión en el exterior mediante adquisiciones en el sector del cemento de Estados Unidos y Canadá, diversificándose así hacia países de la oCDE. Otro gran grupo que se ha diversificado y ha emprendido una dinámica actividad internacional es Odebrecht, que está presente en cuatro continentes, vende en 50 países y obtiene más de un tercio de sus ingresos en el exterior. En el 2005, la empresa Vale, la cuarta del mundo en minería, facturaba $90 \%$ en dólares y $70 \%$ de su ingreso se originaba en el exterior (30\% en Europa y otro $30 \%$ en Asia, particularmente en China y Japón). En los últimos años, concretó compras y se ha establecido en los Estados Unidos, Canadá, Francia, Bahrein y Noruega. Asimismo, emprendió un plan ambicioso de creación de una cartera mundial de proyectos de exploración en tres continentes (los primeros y más importantes, en Perú, Argentina, Gabón, Mozambique y Australia). Por lo demás, Asia (en particular China) pasó a ser uno de los objetivos principales de su expansión comercial. La propiedad de sus acciones también es mayoritariamente internacional: $70 \%$ de sus accionistas no reside en Brasil. En el 2006, la compañía dio un gran paso con la adquisición de la empresa Inco, con base en Canadá, por la cifra sin precedentes de 17.000 millones de dólares.

El de la aeronáutica es otro sector en el que destaca una empresa brasileña con gran presencia internacional, la multilatina Embraer. Como se señaló antes, Embraer es la segunda exportadora brasileña y se ha convertido en emblemática de su país: es líder internacional, como su competidora canadiense Bombardier, pero originaria de un país de economía emergente. Fue fundada en 1969 por el gobierno brasileño, con miras a alcanzar prestigio internacional, y fue privatizada en 1994 (un 20\% del paquete accionario está en manos de un conglomerado de empresas europeas encabezado por Dassault Aviation y por EADs). Actualmente emplea a 15.000 personas. A mediados del 2006, Embraer, cuarta en el mundo en la fabricación de aviones comerciales, firmó un contrato con el Grupo HNA (la aerolínea china) por 100 aviones de reacción valorados en 2.700 millones de dólares, el mayor encargo desde China recibido por esa empresa hasta la fecha. Casi al mismo tiempo, Embraer declaró que reforzaría significativamente su red de apoyo técnico en la región Asia-Pacífico con la creación de un centro logístico de partes y componentes y la instalación de un simulador de vuelo completo para sus aviones de reacción a partir del segundo semestre del 2007.

\section{VI}

\section{De regreso al futuro}

En este punto cabe preguntarse cuáles son los factores que han impulsado el auge inversor de las multilatinas y si ese auge será duradero.

Antes de responder a estos interrogantes, hay que subrayar que la tendencia descrita no es un fenómeno único de América Latina. La aparición de multinacionales que se alzan en los mercados emergentes ya no es una novedad. Las inversiones en el exterior y, en términos más generales, las corrientes de inversión Sur-Sur desde mercados emergentes están en aumento: en el 2005, 
estas últimas representaron más de $30 \%$ de todas las corrientes de IED que fueron a los países en desarrollo (gráficos 18 y 19).

La inversión extranjera directa de los países emergentes está en aumento y las multinacionales latinoamericanas también entraron en esta nueva dinámica. La tendencia se mantendrá en el futuro si se mantienen las condiciones y los incentivos actuales. Por lo que muestran las cifras, la región ha sido un destino clave de la IED, pero se está transformando también en un inversor cada vez mayor en el exterior. Desde el 2000, las empresas brasileñas vienen invirtiendo fuera del país un promedio anual de más de 3.000 millones de dólares, según las estadísticas oficiales de Brasil por las que se calculan las salidas netas al exterior. En el 2004, debido en parte a la fusión de la brasileña Ambev y la belga Interbrew, se alcanzó la cifra sin precedentes de 9.500 millones de dólares, que al año siguiente regresó a un nivel más habitual, de 2.500 millones. Pero en el 2006 se llegaría a un nuevo récord: solo con el nuevo

GRÁFICO 18

Mundo: corrientes de capital Sur-Sur según su naturaleza, 2005

(Porcentaje de las corrientes totales a países en desarrollo)

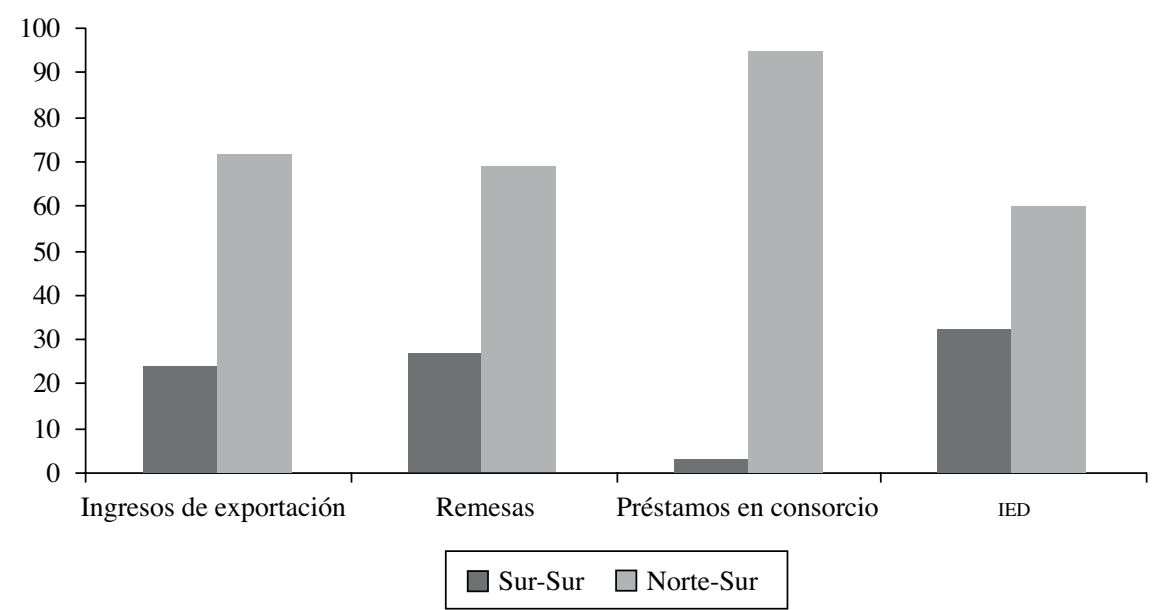

Fuente: elaboración propia a partir de la base de datos Comtrade de las Naciones Unidas, estimaciones de funcionarios del Banco Mundial y Banco Mundial (2006).

GRÁFICO 19

\begin{abstract}
Mundo: inversión extranjera directa Sur-Sur como proporción de la inversión extranjera directa mundial,1995-2003

(Billones de dólares)
\end{abstract}

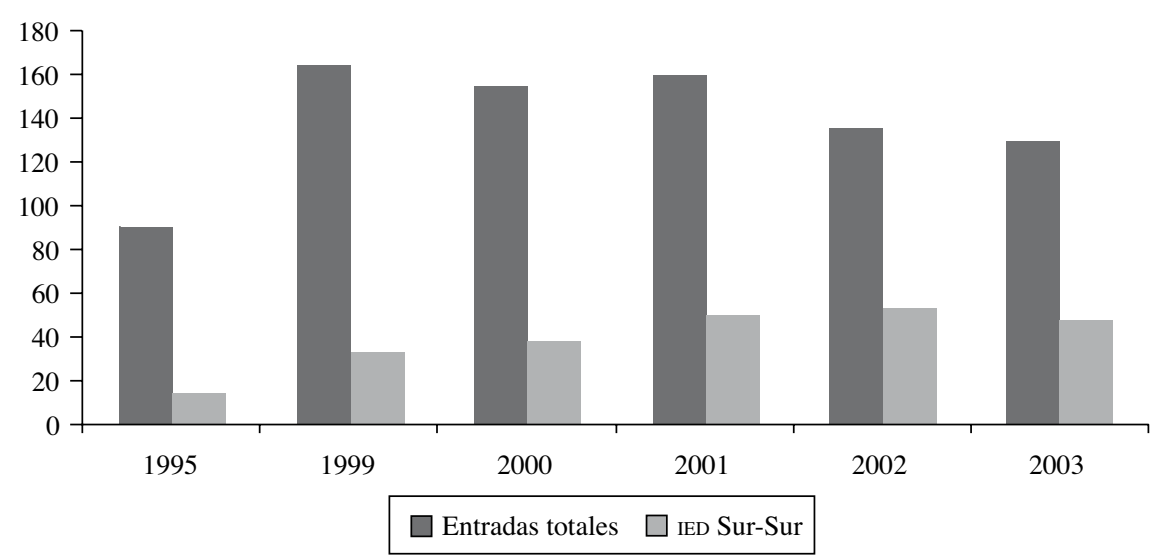

Fuente: elaboración propia a partir de la base de datos Comtrade de las Naciones Unidas, estimaciones de funcionarios del Banco Mundial y Banco Mundial (2006). 
control de Inco por Vale a un costo en efectivo de 19.000 millones de dólares, la inversión brasileña directa en el exterior duplicaría la cifra del año anterior. México muestra un perfil semejante, siendo también reciente el auge de las inversiones directas mexicanas en el exterior. Hasta el 2000, las empresas mexicanas prácticamente no invertían fuera del país, pero a partir de ese año la inversión directa de México en el exterior también registró un promedio de 3.000 millones de dólares por año. En el 2005 subió a la inusitada cifra de casi 6.200 millones de dólares, según cifras oficiales del país. En el 2006, ese monto sería largamente superado: con la sola adquisición de Rinker por Cemex (13.000 millones de dólares), la inversión directa de México en el exterior se duplicaría con creces.

La sostenibilidad de estas tendencias dependerá en parte de la persistencia de los factores que ahora ayudan a las multinacionales emergentes a expandirse en el exterior, inclusive en los países de la OCDE. Merced a las bajas tasas de interés de esos países en los años 2000, se generó un enorme exceso de liquidez y una afanosa búsqueda de rendimientos, todo lo cual demostró ser muy favorable para los mercados emergentes, ya que llevó los márgenes a la baja y redujo el costo del capital para las multinacionales de países emergentes. Al mismo tiempo, los mercados emergentes locales se profundizaron y se hicieron más complejos, en tanto que nuevos inversores ingresaban al mercado de activos con la compra de bonos $\mathrm{y}$ acciones del mundo emergente.

Paralelamente, las transnacionales originarias de economías emergentes trataban de llegar a nuevos mercados, tanto nacientes como más maduros. Armadas de modelos de negocios que combinaban costos bajos con productos y servicios atractivos, modernos sistemas logísticos e informáticos y conocimiento actualizado, empezaron a expandirse en el exterior. Como resultado, Cemex y Vale pasaron a encabezar su sector, Embraer dejó atrás a Bombardier como líder del mercado de aviones de reacción en la región y la empresa Embraco ocupó el primer lugar en el mundo en la fabricación de compresores. La lista seguirá ampliándose a menos que el entorno financiero e industrial del mundo cambie diametralmente.

Algunos de los factores que impulsaron esta expansión son estructurales, como el espectacular surgimiento de tecnologías de telecomunicaciones baratas y la introducción de reformas macroeconómicas fundamentales que mejoraron el perfil de los países emergentes. La necesidad de todas estas empresas de seguir creciendo más allá de sus mercados de origen se tornó más acuciante al ingresar nuevos competidores a sus mercados internos. Para seguir creando valor y mantener la competitividad se vieron obligadas a avanzar otro paso. Y esta necesidad halló un ambiente financiero internacional favorable.

Todas estas compañías, las brasileñas y las mexicanas, pero también las indias y las chinas, tienen algunos elementos en común que explican su auge. Todas provienen de países grandes de veloz crecimiento, capaces de dar soporte a grandes empresas nacionales. Todas disponen de recursos de bajo costo, como la mano de obra o los productos básicos. Todas pudieron crecer en entornos locales difíciles y sobreponerse a la falta de capacidad de gestión, a marcos jurídicos y financieros muy inestables y a sistemas logísticos e infraestructurales deficientes en sus países de origen. Estos obstáculos contribuyeron a transformar a las mejores empresas en organizaciones altamente eficaces, capaces de innovar y adoptar decisiones rápidas para aprovechar nuevas oportunidades. A medida que en los años 1990 otras multinacionales de la OCDE se expandían cada vez más hacia los mercados emergentes, obligaban a las multinacionales emergentes a avanzar y a buscar oportunidades en el exterior.

Otro factor importante de la expansión descrita es, por último, el de las asignaciones de riesgo a la cartera. La diversificación del riesgo ha estado detrás de buena parte de las inversiones que van en busca de mercados y recursos naturales. Las multinacionales latinoamericanas emergentes han procurado también protegerse de los riesgos cambiarios y de las fluctuaciones de los precios de los productos básicos, a la vez que diversificar la localización de activos para mejorar el acceso al capital.

La forma en que esas multinacionales buscan globalizar sus actividades sigue algunos patrones clave que han sido identificados por el Boston Consulting Group (BCG): algunas apuntan a convertirse en marcas mundiales; otras, a convertir su activo técnico en innovación mundial; otro grupo importante va en pos de monetizar los recursos naturales de los países emergentes o proceder a la compra de commodities en otros países; un último grupo - en el que se encuentran empresas madrugadoras como Cemex - se empeña en desplegar nuevos modelos de negocios en múltiples mercados. Según el estudio del BCG, hasta hace poco la expansión en el exterior se debía sobre todo a un crecimiento orgánico (solo $20 \%$ provenía de fusiones y adquisiciones). Pero al mejorar las técnicas financieras y bajar el costo del capital, las fusiones y adquisiciones se están haciendo más atractivas, pues permiten actuar con rapidez y aumentar la participación en el mercado en una sola operación. América Móvil, el operador de telecomunicaciones mexicano, 
gastó más de 5.000 millones de dólares entre el 2001 y el 2005 para marcar presencia en toda América Latina y reproducir su modelo de negocios en otros países. La oleada de gigantescas operaciones de multinacionales emergentes que se observó en el 2006 confirma que las fusiones y adquisiciones se generalizan cada vez más y que esas empresas han superado el temor a participar en licitaciones millonarias, inclusive en los países desarrollados.

Entre las multinacionales emergentes existen también diferencias. Aunque la mayoría de estas empresas actúa en el sector de los productos básicos, otras se desempeñan en importantes actividades manufactureras y de alta tecnología. Pero la diferencia más significativa entre ellas podría no estar basada en sectores y nacionalidades, sino en la naturaleza de su capital. La mayoría de las

\section{VII}

\section{Conclusiones}

En menos de diez años, las multilatinas españolas estudiadas en este artículo se transformaron en empresas de éxito en América Latina y en el resto del mundo. En México y Brasil, otras multilatinas adoptaron la estrategia de la globalización y rebasaron el ámbito de la exportación mercantil. Los casos de Cemex y Vale ilustran que la audacia e innovación en los procesos pueden allanar el camino hacia el liderazgo mundial. Algunas de esas empresas pudieron también aprovechar mercados emergentes - por ejemplo, el de las comunidades hispanas de los Estados Unidos- o sectores como el de la agroindustria, en el cual Arcor, Sadia y Bimbo, entre otras, aprovechan las ventajas competitivas que ofrece la región.

Pero, más allá de estos logros, lo que realmente llama la atención es la magnitud del proceso que emprendieron las empresas analizadas. En solo diez años, México pasó a ser uno de los mayores exportadores de manufacturas del mundo. En el 2005, Brasil superó los 100.000 millones de dólares en exportaciones. El pragmatismo de los empresarios respondió al pragmatismo de las políticas económicas, no solo en Chile, sino también en México y Brasil. ${ }^{10}$ Las políticas monetaria y fiscal sirvieron de anclaje para las estrategias de las empresas.

\footnotetext{
${ }^{10}$ Véase Santiso (2006b) y Feenstra y Hamilton (2006).
}

empresas mexicanas, brasileñas o indias, por ejemplo, están constituidas como sociedades abiertas, tienen cotización bursátil y, sobre todo, ya no están controladas, ni directa ni indirectamente, por el Estado. Y aun en los casos en que el Estado posee buena parte de las acciones, se comportan como empresas privadas. En el caso de las empresas rusas o chinas, los vínculos con el poder son mucho más directos o, cuando son indirectos, mucho más profundos. No ha de sorprender entonces que algunos de los intentos de empresas chinas o rusas por llevar a cabo fusiones o adquisiciones hayan encontrado mayor resistencia en los países de la OCDE. Aun así, han logrado efectuar adquisiciones importantes, como la de IBM por la empresa china Lenovo o, más recientemente, la de una compañía de Cleveland por Norilsk Nickel (Rusia), el mayor productor mundial de níquel.

Las buenas noticias desde América podrían ser que hay más buenas noticias en camino. Las empresas que se han presentado aquí como casos ilustrativos siguen a la vanguardia. Son pocas las empresas de América Latina que se han convertido en líderes mundiales en sus respectivos sectores, como Cemex, Vale y Embraer, pero el mapa mundial de empresas está cambiando con rapidez. En China, India, la República de Corea, Turquía y Sudáfrica están surgiendo grupos multinacionales que, uno tras otro, marcan posiciones importantes tanto a nivel interno como en mercados extranjeros. También América Latina parece tener buenas cartas en la mano. En el futuro, el éxito de sus empresas multinacionales podría igualar los triunfos recientes de las españolas y traer al ruedo más multilatinas exitosas.

Según cifras de las Naciones Unidas, las multinacionales emergentes ya representan la cuarta parte del total de multinacionales importantes del mundo. La mayoría de ellas son todavía relativamente pequeñas, comparadas con sus pares de la OCDE, y tienen un alcance geográfico limitado. Pero la disminución del costo del capital en los últimos años y la creciente ansiedad por expandirse en el exterior están mudando rápidamente el panorama. En el 2006 hubo importantes adquisiciones de empresas por montos cercanos o superiores a los 10.000 millones de dólares o más, realizadas por multinacionales emergentes en países de la OCDE: Vale adquirió Inco, 
Cemex pagó una suma enorme por su rival australiana Rinker, en tanto que Tata Steel compró la acería británica Corus, y Mittal se apoderó de la empresa europea líder del acero, Arcelor. Como se ve, las transnacionales de la OCDE ya no son las únicas adquirentes. En el futuro, veremos en Brasil y México, así como en India, China, Sudáfrica y Rusia, nuevos titanes que toman el control de empresas de países altamente desarrollados. Se trata de un mundo nuevo en el que las multinacionales emergentes - aprovechando un más fácil acceso al capital, así como sus modelos de negocios y la estructura de sus activos- plantean desafíos a las grandes empresas establecidas en los países de la OCDE y las impulsan a adecuarse a la nueva situación.

La creciente conexión Sur-Sur es otra tendencia importante. Las compañías chinas están invirtiendo en Asia, pero ahora también en Sudáfrica y otros países africanos. América Latina no solo está en las pantallas de radar de las empresas chinas, sino que ahora también interesa a empresas indias. Fuera de la relación existente entre Europa y los Estados Unidos, la conexión entre América Latina y Asia podría transformarse en la tendencia más promisoria de este siglo e ilustrar uno de los mayores cambios que registra la economía mundial: lo que llamábamos el Centro (los países de la OCDE), es cada vez menos el centro del comercio y de las corrientes de capital mundiales, en tanto que la Periferia (los países emergentes) es cada vez menos la periferia. Se está haciendo más complicado definir la frontera entre países ricos y pobres. Los llamados países de la OCDE incluyen algunos mercados emergentes, como México, la República de Corea y Turquía.

En las próximas décadas, nuevos titanes emergentes contribuirán a desplazar aún más esa frontera. Las multinacionales de mercados emergentes escribirán parte de esta historia y algunas de ellas serán, sin duda, multilatinas.

Bibliografía

Alfaro, L. y E. Hammel (2006): Latin American multinationals, The Latin American Competitiveness Review 2006, Davos, Foro Económico Mundial. Disponible en: http://www.people.hbs. edu/lalfaro/LatinAmericanMultinationals.pdf

América Economía (2006): varios números, Coral Gables, Florida.

Ananchotikul, S. y B. Eichengreen (2008): Plumbing for Latin American Capital Markets, BIS Papers, № 36, Basilea, Banco de Pagos Internacionales. Disponible en: http://www.bis.org/ publ/bppdf/bispap36.htm

AT Kearney (2008a): New Concerns in an Uncertain world: the 2007 AT Kearney Foreign Direct Investment Confidence Index, Virginia.

(2008b): The Rise of Emerging Markets in Mergers and Acquisitions, Virginia.

Aulakh, P. (2007): Emerging multinationals from developing economies: motivations, paths and performance, Journal of International Management, vol. 13, № 3, Amsterdam, Elsevier.

Baena, C. (2002): Growth beyond national borders: a policy making analysis of PDVSA's internationalization strategy, Latin American Business Review, vol. 3, N ${ }^{\circ}$ 1, Washington, D.C., Carnegie Endowment for International Peace.

Banco Mundial (2006): Global Development Finance 2006, Washington, D.C.

Beausang, F. (2003): Third World Multinationals: ¿Engine of Competitiveness or New Form of Dependency?, Londres, Palgrave.

Blázquez, J., J. Rodríguez y J. Santiso (2006): Angel or Devil? China's Trade Impact on Latin American Emerging Markets, OECD Development Centre Working Paper, No 252, París, junio.

Boston Consulting Group (2006a): China's Global Challenges. The Strategic Implications of Chinese Outbound M\&A, BCG Report, Boston, mayo.

(2006b): The New Global Challenges. How 100 Top Companies from Rapidly Developing Economies are Changing the World, BCG Report, Boston, mayo.

(2007): The 2008 BCG Top 100 New Global Challengers, BCG Report, Boston, diciembre. Disponible en: http://www. bcg.com/impact_expertise/publications/files/Global_Challengers_short_Feb_2008.pdf
CEPAL (Comisión Económica para América Latina y el Caribe) (2008), Inversión extranjera en América Latina y el Caribe anota récord en 2007, Santiago de Chile.

Claessens, S. y S. Schmukler (2007): International Financial Integration Through Equity Markets: Firms from which Countries go Global?, IMF Working Paper, № 138, Washington, D.C., Fondo Monetario Internacional, junio. Publicado también en Journal of International Money and Finance, vol. 26, № 5, Amsterdam, Elsevier, septiembre de 2007.

Coase, R.H. (1994): La empresa, el mercado y la ley, Madrid, Alianza Editorial.

Cuervo-Cazurra, A. (2008): The internationalization of developing country MNEs: the case of multilatinas, Journal of International Management, Amsterdam, Elsevier, por aparecer. Disponible en: http://msbweb.moore.sc.edu/acuervo/Welcome.htm

Cuervo-Cazurra, A. y M. Genc (2008): Converting disadvantages into advantages: developing country MNEs in the least developed countries, Journal of International Business Studies, Londres, Palgrave Macmillan, por aparecer.

Chudnovsky, D., B. Kosacoff y A. López (1999): Las multinacionales latinoamericanas: sus estrategias en un mundo globalizado, Buenos Aires, Fondo de Cultura Económica.

Deutsche Bank Research (2006): Global Champions in Waiting: Perspectives on China's Overseas Direct Investment, Frankfurt am Main.

(2008): Russia's Outward Investment, Frankfurt am Main. Disponible en: http://www.dbresearch.com/

Dunning, J. (1979): Explaining changing patterns of international production: in defence of an eclectic theory, Oxford Bulletin of Economics and Statistics, vol. 41, N ${ }^{\circ}$, Oxford, Blackwell Publishing.

(1980): Towards an eclectic theory of international production: some empirical tests, Journal of International Business Studies, vol. 11, № 2, Londres, Palgrave Macmillan.

(1995): Reappraising the eclectic paradigm in an age of alliance capitalism, Journal of International Business Studies, vol. 26, $\mathrm{N}^{\circ}$ 2, Londres, Palgrave Macmillan. 
Feenstra, R. y G. Hamilton (2006): Emergent Economies, Divergent Paths, Cambridge, Massachusetts, Cambridge University Press.

Financial Times (2006): varios números, Londres.

Fostel, A. y G. Kaminsky (2007): Latin America's Access to International Capital Markets: Good Behaviour or Global Liquidity?, NBER Working Paper Series, No 13194, Cambridge, Massachusetts, National Bureau of Economic Research.

Gammeltoft, P. (2008): Emerging multinationals: outward FDI from BRICs countries, International Journal of Technology and Globalisation, vol. 4, No 1, Ginebra, Inderscience Publishers. Disponible en: http://ir.lib.cbs.dk/download/ISBN/X075239.pdf

Goldstein, A. (2007): Multinational Companies from Emerging Economies: Composition, Conceptualization and Direction in the Global Economy, Londres, Palgrave.

(2008): A Latin American global player goes to Asia: Embraer in China, International Journal of Technology and Globalisation, vol. 4, $\mathrm{N}^{\circ} 1$, Ginebra, Inderscience Publishers.

Guillén, M. (2005): The Rise of Spanish Multinationals: European business in the Global Economy, Cambridge, Cambridge University Press.

Hardouvelis, G., A. Dimitrios Malliaropulos y R. Priestley (2007): The impact of EMU on the equity cost of capital, Journal of International Money and Finance, vol. 26, $\mathrm{N}^{\mathrm{o}}$ 2, Amsterdam, Elsevier, marzo.

Jones, G. (2005): Multinationals and Global Capitalism from the Nineteenth to Twenty First Century, Nueva York, Oxford University Press.

Khanna, T. (2008): Billions of Entrepreneurs: How China and India Are Reshaping Their Futures and Yours, Boston, Massachusetts, Harvard Business School Press.

Khanna, T. y Y. Yafeh (2007): Business groups in emerging markets: paragons or parasites?, Journal of Economic Literature, vol. 45, $\mathrm{N}^{\circ}$ 2, Nashville, Tennessee, American Economic Association.

Kosacoff, B., J. Forteza y otros (2001): Globalizar desde Latinoamérica: el caso de Arcor, Buenos Aires, McGraw-Hill Interamericana.

Lall, Sanjaya (comp.) (1983): The New Multinationals: the Spread of Third World Enterprises, Chichester, Wiley.

Levy-Yeyati, E., U. Panizza y E. Stein (2007): The cyclical nature of Nort-South FDI flows, Journal of International Money and Finance, vol. 26, № 1, Amsterdam, Elsevier.

ocDE (Organización de Cooperación y Desarrollo Económicos) (2007): Latin American Economic Outlook 2008, París, Centro de Desarrollo de la OCDE.
Oman, Ch. (comp.) (1986): New Forms of Overseas Investment by Developing Countries: the Case of India, Korea and Brazil, París, Centro de Desarrollo de la ocDE.

Rugman, A. (2005): The Regional Multinationals, Cambridge, Cambridge University Press.

(2007): Multinational Enterprises from Emerging Markets, Indiana, Kelly School of Business, Indiana University. Disponible en: http://www.g7.utoronto.ca/conferences/2007/ rugman2007.pdf

Rugman, A. y L. Jing (2008): Will China's multinationals succeed globally or regionally?, European Management Journal, vol. 25, $\mathrm{N}^{\circ}$ 5, Amsterdam, Elsevier. Disponible en: http://www.kelley. indiana.edu/rugman/research.htm

Santiso, J. (2006a); La emergencia de las multinacionales latinas, Claves de la economía mundial, Madrid, Instituto Español de Comercio Exterior (ICEX).

(2006b): Latin America's Political Economy of the Possible: Beyond Good Revolutionaries and Free Marketeers, Cambridge, Massachusetts, MIT Press.

(2007a): La internacionalización de las empresas españolas: hitos y retos, Información comercial española, ICE: Revista de economía, $\mathrm{N}^{\circ} 839$, Madrid, Ministerio de Industria, Comercio y Turismo, noviembre-diciembre.

(2007b): La transformación empresarial española, Política exterior, vol. 21, $\mathrm{N}^{\mathrm{o}} 115$.

Sauvant, K. (comp.) (2008), The Rise of Transnational Corporations from Emerging Markets, Nueva York, Edward Elgar.

Tolentino, P. E. (1993): Technological Innovation and Third World Multinationals, Londres, Routledge.

UNCTAD (Conferencia de las Naciones Unidas sobre Comercio y Desarrollo) (2006): World Investment Report 2006. FDI from Developing and Transition Economies: Implications for Development, UCTAD/WIR/2006, Ginebra, Naciones Unidas. Publicación de las Naciones Unidas, $\mathrm{N}^{\circ}$ de venta: E.06.II.D.11.

Van Agtmael, A. (2007): The Emerging Markets Century: How a New Breed of World-Class Companies Is Overtaking the World, Nueva York, Free Press.

Vernon, R. (1966): International investment and international trade in the product cycle, The Quarterly Journal of Economics, vol. 80, $\mathrm{N}^{\circ} 2$, Cambridge, Massachusetts, The MIT Press.

Wells, L. (1983): Third World Multinationals: the Rise of Foreign Direct Investment from Developing Countries, Cambridge, Massachusetts, The MIT Press. 